\title{
Investigation of the Use and Feasibility of Speed Warning Systems
}




\section{Technical Report Documentation Page}

\begin{tabular}{|c|c|c|}
\hline $\begin{array}{l}\text { 1. Report No. } \\
\text { DOT HS } 811996\end{array}$ & 2. Government Accession No. & 3. Recipient's Catalog No. \\
\hline \multirow{2}{*}{\multicolumn{2}{|c|}{$\begin{array}{l}\text { 4. Title and Subtitle } \\
\text { Investigation of the Use and Feasibility of Speed Warning Systems }\end{array}$}} & $\begin{array}{l}\text { 5. Report Date } \\
\text { May } 2014\end{array}$ \\
\hline & & 6. Performing Organization Code \\
\hline \multicolumn{2}{|c|}{$\begin{array}{l}\text { 7. Author(s) } \\
\text { De Leonardis, D., Huey, R., and Robinson, E. }\end{array}$} & 8. Performing Organization Report No. \\
\hline \multirow{2}{*}{\multicolumn{2}{|c|}{$\begin{array}{l}\text { 9. Performing Organization Name and Address } \\
\text { Westat, Inc. } \\
\text { 1600 Research Blvd } \\
\text { Rockville, Maryland } 20850\end{array}$}} & 10. Work Unit No. (TRAIS) \\
\hline & & $\begin{array}{l}\text { 11. Contract or Grant No. } \\
\text { DTNH22-06-D-00033 } \\
\text { Task Order } 0003\end{array}$ \\
\hline \multirow{2}{*}{\multicolumn{2}{|c|}{$\begin{array}{l}\text { 12. Sponsoring Agency Name and Address } \\
\text { National Highway Traffic Safety Administration } \\
\text { Office of Behavioral Safety Research } \\
1200 \text { New Jersey Avenue SE. } \\
\text { Washington, DC } 20590\end{array}$}} & $\begin{array}{l}\text { 13. Type of Report and Period Covered } \\
\text { FINAL REPORT } \\
\text { September } 2009 \text { - December } \\
2012\end{array}$ \\
\hline & & 14. Sponsoring Agency Code \\
\hline
\end{tabular}

15. Supplementary Notes

Randolph Atkins was the Contracting Officer's Technical Representative.

\section{Abstract}

This report summarizes a feasibility evaluation of a speed monitoring system that provided speed warning feedback to drivers enrolled in a voluntary program, with particular emphasis on at-risk drivers, especially chronic speeders. This project included a review of driver monitoring and feedback products, a focus group of chronic speeders, and a naturalistic field study. The field study was designed to determine the effects of immediate feedback on driver behavior as well as answering a "feasibility" question related to implementing such a program on a larger scale.

Drivers with at least three speeding violations in the past three years were recruited through the Maryland Motor Vehicle Administration. After a two-week baseline period, the alert system was activated and driving behavior was monitored for any changes for approximately four weeks. (Some participants experienced the alerts for eight weeks.) Subjects were monitored (silently) for a follow-up phase of two weeks (or four weeks; for the longer duration subjects). During the treatment phase, alerts were provided to the drivers when their speeds exceeded the posted speed limit by more than $8 \mathrm{mph}$.

The findings are encouraging, and suggest that the verbal alerts provided were successful in producing statistically significant but small short-term changes in driving behavior. Overall, the average proportion of speeding above the alert threshold declined significantly during the course of the treatment phase, indicating that the presence of alerts does have a deterring effect on speeding behavior. Once the alerts were silenced, there was evidence suggesting a sustained change in driving behavior for some participants. Although the proportion of speeding above the threshold during the two-week follow-up period was higher than the proportion of speeding during the treatment phase, the follow-up speeds were lower than those recorded during the baseline phase for some participants.

17. Key Words

Speeding, Speeding Countermeasures, Unsafe Driving, Speed Monitoring Devices

19 Security Classif. (of this report)

Unclassified
20. Security Classif. (of this page)

Unclassified
18. Distribution Statement

Document is available to the public from the National Technical Information Service www.ntis.gov 


\section{Acknowledgements}

The authors thank the drivers who agreed to participate in this study. This research would not have been possible without the full support and cooperation of the Maryland Motor Vehicle Administration and support staff. We would like to acknowledge Dr. Susan Ferguson who reached out to various contacts within the insurance industry in an attempt to identify a sample population. 


\section{TABLE OF CONTENTS}

Chapter

$\underline{\text { Page }}$

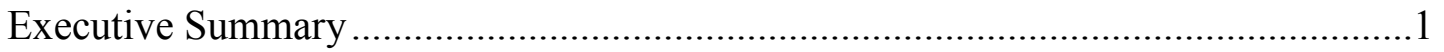

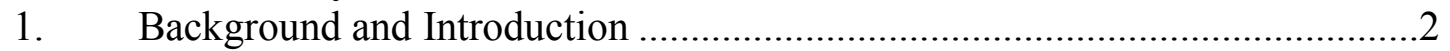

2. Speed Monitoring/Feedback Device Market Survey Overview ........................

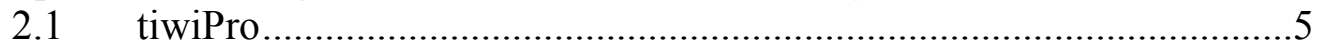

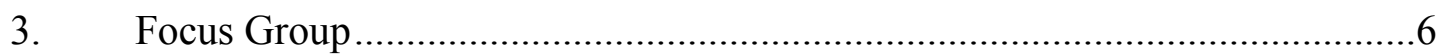

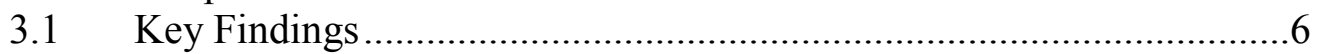

3.1.1 Driving Behavior and Speeding Violations ..............................6

3.1.2 Speed Monitoring Devices........................................................

3.1.3 Third Party Knowledge of Driving Behavior ...........................

3.1.4 Programs and Incentives .........................................................

4. Field Data Collection In-Vehicle Naturalistic Driving Study...........................

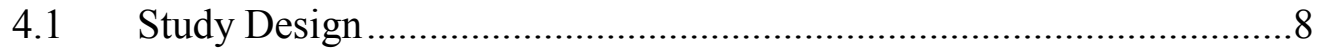

4.2 Participant Recruitment ..............................................................

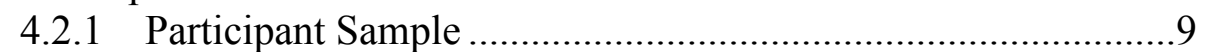

4.3 Data Collection Procedures..................................................................11

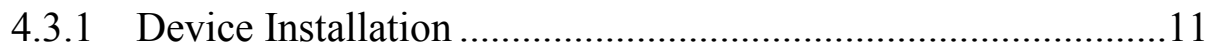

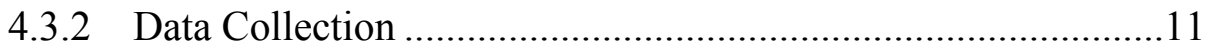

4.3.3 Device Removal and Debrief................................................13

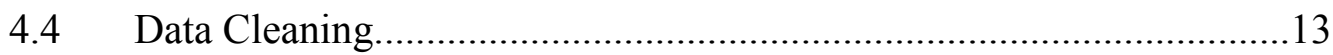

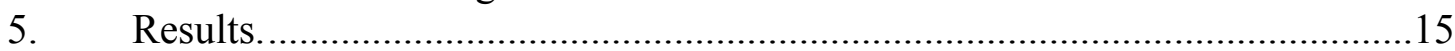

5.1 Short-Duration Participants ................................................................

5.1.1 Driving Over the Speed Limit...................................................17

5.1.2 Driving Up to $8 \mathrm{mph}$ Above the Posted Speed Limit ................19

5.1.3 Driving Over $8 \mathrm{mph}$ Above the Posted Speed Limit .................20

5.1.4 Driving at Least $20 \mathrm{mph}$ Over the Posted Speed Limit .............22

$5.2 \quad$ Habitual Versus Non-Habitual Speeders ..................................................23

5.2.1 Habitual Versus Non-Habitual Speeders Driving Over

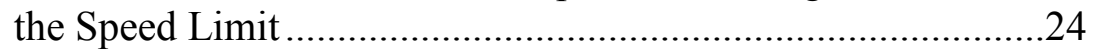

5.2.2 Habitual Versus Non-Habitual Speeders Driving up to $8 \mathrm{mph}$ Above the Posted Speed Limit ......................................25

5.2.3 Habitual Versus Non-Habitual Speeders Driving Over 8 mph Above the Posted Speed Limit.........................................27

5.2.4 Habitual Versus Non-Habitual Speeders Driving at Least 20 mph Over the Posted Speed Limit...............................28

5.3 Ticket Participants ............................................................................29

5.3.1 Ticketed Participants Driving Over the Speed Limit.................30

5.3.2 Ticketed Participant Speeding up to $8 \mathrm{mph}$...............................30

5.3.3 Ticketed Participants Driving Over $8 \mathrm{mph}$ Above the Posted Speed Limit ...................................................................... 31

5.3.4 Ticket Participants Driving at Least $20 \mathrm{mph}$ Over the Posted Speed Limit 


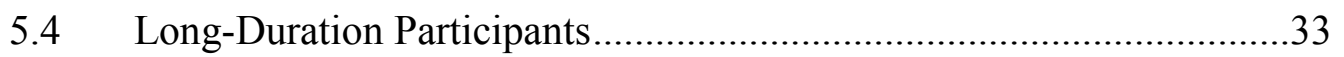

5.4.1 Long-Duration Participants Driving Over the Speed Limit ...........................................................................33

5.4.2 Long-Duration Participants Speeding Up to $8 \mathrm{mph}$...................34

5.4.3 Long-Duration Participants Speeding Over $8 \mathrm{mph}$......................35

5.4.4 Long-Duration Participants Speeding at Least $20 \mathrm{mph}$ Over the Posted Speed Limit ......................................................36

5.5 Short-Duration Participants Speeding Behavior Related to

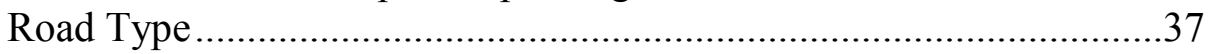

5. 5.1 Driving Over the Speed Limit by Road Type …….....................37

5.5.2 Speeding Up to $8 \mathrm{mph}$ by Road Type.........................................38

5.5.3 Speeding Over $8 \mathrm{mph}$ by Road Type........................................39

5.5.4 Speeding at Least $20 \mathrm{mph}$ Over the Posted Limit by

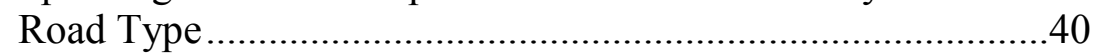

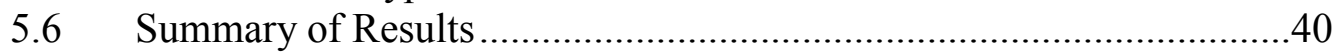

6. Feasibility of Implementing a Large Scale Program. ............................41

$6.1 \quad$ User Acceptance ............................................................................ 41

6.2 Feasibility of Larger Scale Deployment …………................................43

6.2.1 Subject Recruitment.................................................................43

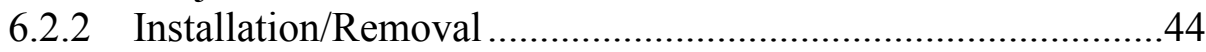

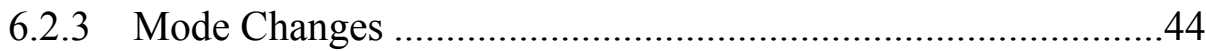

6.2.4 Account Setup ...................................................................4

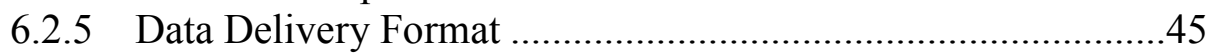

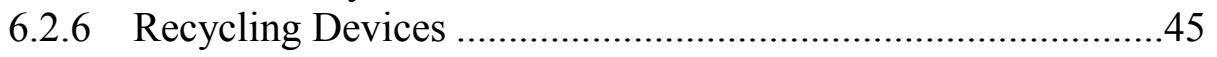

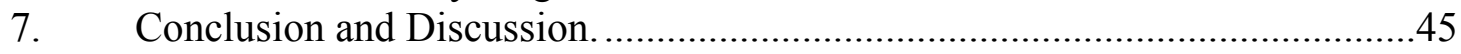

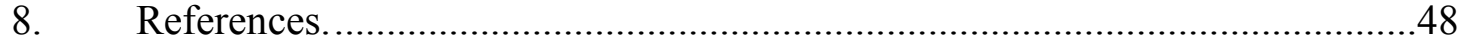

Appendix: Explanation of Statistical Approach .............................................50 


\section{List of Figures}

1. tiwiPro device attached to the windshield ................................................

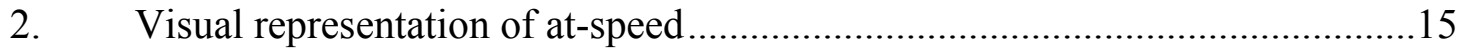

3. Graphical depiction of speeding behavior measures ...................................16

4. Mean proportion of driving over the posted speed limit for participants in short condition measures....................................................18

5. Mean proportion of driving over the posted speed limit for all participants in short condition by age and phase ........................................19

6. Mean proportion of driving up to $8 \mathrm{mph}$ over the posted speed limit for participants in short condition ..............................................................20

7. Mean proportion of driving up to $8 \mathrm{mph}$ over the posted speed limit for all participants in short condition by age and phase.................................20

8. Mean proportion of each trip driving over $8 \mathrm{mph}$ above the posted speed limit for participants in short condition ..............................................21

9. Mean proportion of each trip driving over $8 \mathrm{mph}$ above the posted speed limit for all participants in short condition by age and phase ...............22

10. Mean proportion of each trip driving at least $20 \mathrm{mph}$ over the posted speed limit for participants in short condition .............................................23

11. Mean proportion of each trip driving at least $20 \mathrm{mph}$ over the posted speed limit for participants in short condition by age and phase.

12. Mean proportion of each trip driving over the posted speed limit for habitual speeders in short condition

13. Mean proportion of each trip driving over the posted speed limit for habitual and non-habitual speeders in short condition by phase ....

14. Mean proportion of driving up to $8 \mathrm{mph}$ over the posted speed limit for habitual speeders in short condition ....................................................26

15. Mean proportion of driving up to $8 \mathrm{mph}$ over the posted speed limit for habitual and non-habitual speeders in short condition by phase

16. Mean proportion of each trip driving over $8 \mathrm{mph}$ above the posted speed limit for habitual speeders in short condition .....

Mean proportion of each trip driving over $8 \mathrm{mph}$ above the posted speed limit for habitual and non-habitual speeders in short condition by phase

18. Mean proportion of driving at least $20 \mathrm{mph}$ over the posted speed limit for habitual speeders in short condition.....

19. Mean proportion of driving at least $20 \mathrm{mph}$ over the posted speed limit for habitual and non-habitual speeders in short condition by phase

20. Mean proportion of ticketed drivers driving over the speed limit in short duration condition .....

21. Mean proportion of ticketed drivers driving up to $8 \mathrm{mph}$ above the posted speed limit in short duration condition....

22. Mean proportion of ticketed drivers driving over $8 \mathrm{mph}$ above the posted speed limit in short duration condition 
23. Mean proportion of ticketed drivers driving at least $20 \mathrm{mph}$ over the posted speed limit in duration condition

24. Mean proportion of driving over the speed limit in long-duration condition

25. Mean proportion of driving up to $8 \mathrm{mph}$ above the posted speed limit in long-duration condition 35

26. Mean proportion of driving over $8 \mathrm{mph}$ above the posted speed limit in long-duration condition. .36

27. Mean proportion of driving at least $20 \mathrm{mph}$ over the posted speed limit in long-duration condition....

28. Mean proportion of driving over the speed limit by road type in short duration condition 38

29. Mean proportion of driving up to $8 \mathrm{mph}$ above the posted speed limit by road type in short duration condition.

30. Mean proportion of driving over $8 \mathrm{mph}$ above the posted speed limit by road type in short duration condition 39

31. Mean proportion of driving over $75 \mathrm{mph}$ in short duration condition

\section{List of Tables}

1. Maryland Counties Included in Participant Recruitment..................................10

2. Age and Gender Distribution of Participants................................................10

3. Record Counts for Analysis .......................................................................15 


\section{Executive Summary}

Speeding behavior is pervasive in the United States and commonly accepted within the driving culture (Corbett, 2000). While traditional countermeasures can be successful at reducing speeding behavior, they have limitations that may reduce their overall effectiveness. One new approach for solving the speeding problem is through the use of a vehicle-based monitoring and feedback system.

The current report summarizes a feasibility evaluation of a viable commercial system that provided speed warning feedback to drivers enrolled in a voluntary program, with particular emphasis on atrisk drivers (i.e., chronic speeders). This project included a thorough review of driver monitoring and feedback products, a focus group of chronic speeders, and a naturalistic field study. The field study was designed to determine the effects of immediate feedback on driver behavior as well as answering a "feasibility" question related to implementing such a program on a larger scale.

After a review of available devices, the tiwiPro was selected, primarily because of its unique ability to provide immediate, speed limit-relevant feedback to speeding drivers on a real time basis. Drivers with at least three speeding violation in the past three years were recruited through the Maryland Motor Vehicle Administration (MVA). After a two-week baseline period, the alert system was activated and driving behavior was monitored for any changes for approximately four weeks. (Some participants experienced the alerts for eight weeks.) Subjects were monitored (silently) for a followup phase of two weeks (or four weeks; for the longer duration subjects). During the treatment phase, alerts were provided to the drivers when their speeds exceeded the posted speed limit of any given road by more than $8 \mathrm{mph}$.

The findings of the study are encouraging, and suggest that the verbal alerts provided by the system were successful in producing statistically significant but small short-term changes in driving behavior. Overall, the average proportion of speeding above the alert threshold declined significantly during the course of the treatment phase, indicating that the presence of audio alerts does have a deterring effect on speeding behavior. In addition, once the treatment was lifted, there was evidence suggesting a sustained change in driving behavior for some participants. Although the proportion of speeding above the threshold during the two-week follow-up period was higher than the proportion of speeding during the treatment phase, the follow-up speeds were lower than those recorded during the baseline phase.

It is also important to note that the significance of the effects for the participants in the longduration condition could not be addressed with confidence, due to the small sample size (five participants). However, the trends seem to echo those from the short duration condition, providing preliminary evidence for the potential to use these systems as a tool for reducing speeding behavior. It is important to note that the treatment and follow-up phases of this study were not extensive, and that a longer duration period is recommended in order to test the long-lasting effects of this kind of system on driving behavior. 


\section{Background and Introduction}

Speeding behavior is pervasive in the United States and commonly accepted within the driving culture (Corbett, 2000). Approximately three-quarters of all drivers in the 2002 National Highway Traffic Safety Administration national survey reported exceeding the posted speed limit. Specifically, 78 percent of those interviewed admitted to speeding on the interstates, 83 percent on non-interstate multilane roads, 78 percent on two-lane roads, and 73 percent on city streets within the past month (NHTSA, 2004). In addition, excessive speed is a contributing factor in a high proportion of severe and fatal crashes (Elvik, Christensen, \& Amundsen, 2004). Speeding-related crashes are responsible for an estimated $\$ 40$ billion in economic losses each year and were associated with the loss of 10,395 lives (31\% of all highway fatalities) in 2010 (NHTSA, 2012). There has been little change in the proportion of speed related crashes over the past 10 years.

Although most drivers admit to exceeding the posted speed limit, there are subgroups of the driving population that tend to speed more often (Webster \& Wells, 2000; Zuckerman \& Neeb, 1980). For example, for drivers involved in fatal crashes, young males are the most likely to be speeding. In 2010, 39 percent of male drivers 15 to 24 years old involved in fatal crashes were speeding at the time of the crash (NHTSA, 2012).

Despite decades of efforts in traffic engineering, driver training, high-visibility enforcement, and public education, speeding is a behavior that remains resistant to change. Although traditional approaches (e.g., expanded regular patrols or designated patrols) and more recent innovations (e.g., automated enforcement) certainly help mitigate the problem, these approaches have limitations in terms of their effectiveness, cost, implementation time, and practicality of coverage. For example, high-visibility enforcement programs are costly and can take up to 4 to 6 months to plan, publicize and implement. Their effectiveness is often site-specific, restricted to locations (roadways) that have been targeted for enforcement due to increase number of speed related crashes, and drivers other than the general speeding population are often affected by these countermeasures. With regard to the automated enforcement programs, the impact of enforcement is delayed, since drivers are often unaware that they have committed a violation for several weeks, because speeding citations are mailed to drivers after law enforcement reviews the evidence. In addition, automated speed enforcement programs are often viewed as intrusive on individual privacy or as a revenue generator, rather than as a means of improving safety.

A comprehensive speed management program requires multiple approaches, as no single speed management approach can effectively reduce this behavior among the general speeding population by itself. A key component of the Speed Management Strategic Initiative has been to emphasize the interdisciplinary approach whereby roadway engineering, enforcement, education, and judiciary are all critical components. An alternative approach to solving the speeding problem would be to use a variety of speed management strategies unpredictably, or to specifically pair a strategy with an individual driver or behavior type where it might be most successful. 
One new approach for solving the speeding problem is through the use of a vehicle-based monitoring and feedback system. This particular countermeasure is less affected by the limitations described earlier, due largely to the fact that this countermeasure is paired with an individual driver. That is, the device is constantly monitoring a given driver, allowing feedback to be immediate and relevant in time. Although these devices have not been deployed widely in the United States, they have been shown to provide a significant mean reduction in vehicle speeds (Lei \& Carsten, 2012; Regan et al., 2006; Reagan, 2011). Currently, a variety of commercial and experimental systems exist that can be installed in an individual's vehicle to monitor various aspects of driving behavior and vehicle control. These frequently include speed and indices of severe maneuvers (e.g., hard deceleration), and may include a wide variety of other measures (e.g., lateral accelerations, video and audio records, seat belt status, GPS tracking, geo-fencing, fuel economy, hazard proximity, or indices of attention or drowsiness). Such technologies could easily be deployed in personal vehicles to provide drivers with feedback when they exceed absolute or posted speeds by a preset amount.

Recent evaluations of driver monitoring programs offer promise, often reporting substantial decreases in risky behaviors, including speeding (Regan et al., 2006). Unverified reports from fleet owners claim that the presence of this device in their vehicles has led to precipitous decreases in violations and crash rates. Several studies found that equipping teens' vehicles with in-vehicle monitoring devices helped reduce risky driving behavior by giving feedback about driving behavior to both teenagers and their parents (IIHS, 2010). In addition, insurance companies are actively pursuing and commercially employing these technologies.

While these studies offer promise, there are reasons for caution as well. These include (1) driver participation is not fully voluntary, with the driver under the influence of a third party who often shares in the feedback, such as a parent (for teens), or an employer (Chorlton \& Conner, 2012); (2) the tested systems often include more extensive feedback than just speed warnings, and it is not known what aspects are contributing to effectiveness; (3) a number of the evaluations have been informal, small, poorly controlled, or conducted by parties with inherent self-interest in the outcomes; and (4) the findings of benefits are not uniformly substantial or sustained.

Commercial development of these systems is likely to continue, but commercial enterprises are unlikely to publish peer-review quality data on how these systems work, how well they work, and under what circumstances. The current report summarizes an evaluation of a viable commercial system that provides speed warning feedback to drivers enrolled in a voluntary program, with particular emphasis on at-risk drivers (i.e., chronic speeders). The research involved a comprehensive approach for exploring driver monitoring systems in terms of their ability to monitor and reduce speeding and crashes among adult drivers with a history of speeding violations. This project included a thorough review of current products that can monitor driver speed and provide feedback on performance. A focus group was convened with a subset of participants who were identified as chronic speeders, to examine the driver behavior and characteristics of this subgroup, identify incentives that might be adequate or optimal for achieving a full voluntary sample in the feasibility study, and to gather data on user response and acceptance issues. The field data collection involved a naturalistic driving study that was devised with recognition that there were two aspects to this study. First, there was the "evaluation," to determine the effects of device exposure on driver behavior for this group. Second, there was the "feasibility" question, regarding the successes and challenges of implementing the program with a larger scale sample of chronic speeders. 


\section{Speed Monitoring/Feedback Device Market Survey Overview}

The research team first reviewed the large market of available devices and services to identify devices that might meet the specific needs of this project. The study required that a device, at minimum, could provide feedback to a study group of drivers in real-time, and could collect travel speed data to be used for assessing the long-term implications of their exposure to this type of feedback. Thirty-five existing in-vehicle speed monitoring/warning devices were reviewed in order to select those devices that were most compatible with the design and goals of this study. In structuring the review, each of the following criteria was considered.

- Ability to record data on driving behavior (e.g., ignition, speed, braking, turning, etc.)

- Ability to monitor speed by road segment using a posted speed limit database and Global Positioning System (GPS)

- Ability to compare vehicle speed to posted speed and provide feedback in a real-time, based on a predefined threshold per limit category

- Use of a speed limit database that is relatively accurate and complete, and allows detected errors to be reported and corrected

- An interactive web portal for setup and monitoring

- Custom alerts via call, text, or e-mail

- Ease of installation in the participant's vehicles

- Data recorded that includes, at a minimum, number of trips, mileage, speeds, sudden accelerations and decelerations, number of warnings

- Basic data and reports that can be enhanced by custom reports and raw, time sampled data

- The ability to differentiate users

- Data that is easily downloadable for subsequent analyses

- A system which includes a built-in warning system that can provide the driver with a feedback whenever he/she exceeds a preset threshold over each limit category

- A warning function that can be turned off to record data covertly and turned on to provide driver feedback

- Ability to report tampering

- A device that minimizes the potential for vehicle owner concerns (e.g., intrusiveness and aesthetics, taking up cargo space)

- Power drain or other concerns about vehicle performance or damage are addressed

Based on the review, two devices were selected for initial testing under study conditions. While both met most of the criteria necessary for inclusion in the study, the tiwiPro was the only device capable of providing real-time, tailored coaching feedback to the posted speed limit along the travelled roadways. That is, while in the vehicle, the driver passively receives verbal feedback on whether 
he/she is traveling above a given posted speed limit threshold. The alert would provide an audible computerized voice stating, "Speeding violation" repeatedly for as long as the participant's speed was above the trigger threshold of $8 \mathrm{mph}$ over the posted speed, and was the same regardless of how much over the trigger threshold the participant was driving.

Given that one of the objectives of the current study is to examine the effects of speed monitoring and feedback exposure on driver behavior, it was critical that the feedback be immediate, reliable, and relevant. Therefore, the tiwiPro was selected to best facilitate the current research design.

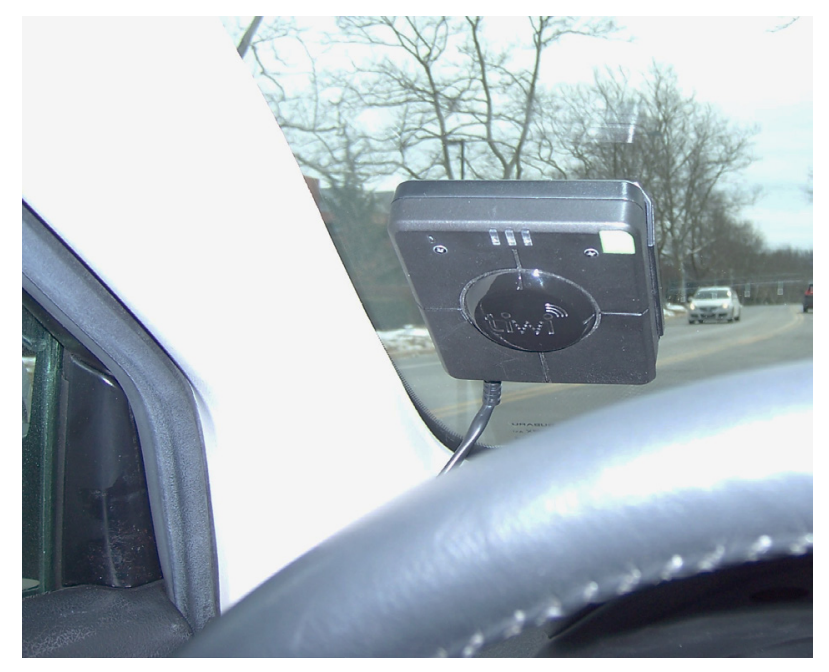

Figure 1. tiwiPro device attached to the windshield

\section{1 tiwiPro}

Produced by inthinc, the tiwiPro unit is about 4.25" x 5" with a cord extending from the lower side of the device to allow connection to the vehicle's on-board diagnostic (OBD-II) connector (typically located under the dash, near the steering wheel). Installation and initial setup is relatively simple and quick (approximately 15 minutes).

Using GPS and a database of posted speed limits by roadway segment, the unit is capable of providing the driver with real-time feedback about the speed relative to the posted speed limit along the travelled roadways. At the time of the review, tiwiPro was the only vendor capable of providing this level of functionality in real-time. That is, while in the vehicle, the driver can passively receive feedback on whether he/she is traveling a predefined speed above a posted speed limit. Once the predefined speed threshold is breached, the driver receives both a visual message via an LED light and a verbal message regarding the nature of the violation. For the visual notification, a red LED light comes on just prior to the verbal alert and remains on until the vehicle speed drops below the predefined speed threshold. Verbal notifications include "Speeding Violation" and "Aggressive Driving." The verbal alerts are repeated every few seconds until the vehicle speed drops below the predefined speed threshold.

The system also provides the user with the ability to suggest corrections to the database of posted speed limits. This may be important for frequently traveled road segments, if a driver often experiences alerts based on seemingly erroneous posted limits. False notifications may reduce the 
overall effectiveness of the device in reducing speeding behavior, and driver acceptance of the system.

Another important feature related to the study design and available through the tiwiPro system is the ability to detect tampering. As such, it provides indications to the database when the device has been removed, unplugged, or opened by unauthorized personnel.

Finally, inthinc is capable of providing time-sampled reporting of location-based information for each participant's vehicle on a periodic basis. Data can be delivered in comma-separated value (.CSV) form or in an Excel spreadsheet for further review, reporting, and analysis.

\section{Focus Group}

The focus group had two general objectives. First, it served as a useful tool to explore a variety of key issues related to the study design; and second, it helped identify potential pitfalls in the design and selected feedback device from the perspective of the target population. The focus group was conducted in Rockville, Maryland, using Westat's focus group facilities, and included various issues related to driving behavior and acceptability of using an in-vehicle speed monitoring system as a way to reduce speeding and crashes for chronic speeders.

Eight participants were recruited through advertisement in the Westat intranet and placing flyers. Participation in the focus group was open to all Westat employees, as well as family members and acquaintances. All participants were over 21 years old, in possession of valid driver licenses, and drove passenger vehicles on a regular basis. Five participants traveled at least 100 miles a week, and three reported traveling 50 to 99 miles per week. All participants received multiple speeding citations within the previous three years, most between 3 to 5 citations, and a number received multiple warnings in addition to the violations.

\subsection{Key Findings}

Several major themes emerged during the focus group discussion. The major themes were specific broad concerns that stood out based on commonality among the focus group participants, the intensity of the discussion, the diversity of the described behavior, or the significance of the issue.

\subsubsection{Driving Behavior and Speeding Violations}

When asked about opinions regarding the posted speed limits, most participants indicated that speed limits are reasonable; however, a number of participants indicated that the most important indicator for determining their speed on a given roadway is the flow of traffic.

Drivers reported often traveling more than 15 miles above the speed limit at times, and being unaware of their actual speed. Some of the participants indicated that they monitor their speedometers on a regular basis, but this behavior is often related to the presence of law enforcement officers and speed enforcement cameras. Overall, participants adopted driving 
strategies in order to avoid violations. While participants unanimously indicated that they would slow down in the presence of law enforcement or speed enforcement cameras, they viewed them as a short term deterrent, and they said they resume their speed once out of the range of the officer or camera.

\subsubsection{Speed Monitoring Devices}

Participants were introduced to the speed monitoring device and viewed a video demonstration of the tiwiPro. The video illustrated where and how the tiwiPro would be installed in their vehicle, as well as how the system would alert the driver if a speeding violation occurred. Opinions regarding the device were mixed. When discussing the different features of the device, participants were clear that they would want to be able to calibrate the device so that the speed threshold for alert was not set at the posted speed limit for a given roadway; that is, the threshold was set at some speed 5 to 10 mph above the posted speed limit. In addition, others recommended that the device be able to identify drivers, so that people not enrolled in the program would not have to experience the alerts.

Participants were quick to point out that any change resulting from exposure to the device might be only short term, similar to other methods used to alter speeding behavior. Some felt that they would eventually figure out how to defeat or ignore the warnings. One participant noted that it might be embarrassing to explain to a co-worker, and might have a negative connotation similar to that associated with the breathalyzer used for DWI drivers.

\subsubsection{Third Party Knowledge of Driving Behavior}

Regarding third-party knowledge of the data, participants were, for the most part, not worried about participating in a research study. However, they expressed some suspicions regarding law enforcement, motor vehicle administration, and insurance companies having information related to their driving behavior. Participants felt that providing information to agencies other than researchers would only have negative consequences including the revocation of their driver licenses and increased insurance premiums. If the program is intended to involve voluntary participation, providing information to these agencies would severely limit the likelihood of recruiting individuals.

\subsubsection{Programs and Incentives}

Most participants were willing to discuss the possibility of volunteering for a speed monitoring program, and agreed that the device would serve as more of a deterrent to speeding than a driving class.

Gas cards or monetary incentive would serve as an attractive incentive for most participants. The amount varied from $\$ 25$ to $\$ 200$, depending on the duration of the program. In general, the idea of a cash incentive up front, rather than a raffle or prize, was the method that received the most positive feedback from the group.

\section{Field Data Collection In-vehicle Naturalistic Driving Study}

The experimental design and procedures for the in-vehicle study were devised to provide both quantitative and qualitative measures of the effectiveness of speed monitoring devices for reducing 
travel speeds among chronic speeders. It also explored issues related to implementing the program with the sample of adult speeders and promoting user acceptance. The procedures and design of the in-vehicle pilot study were based on previous research, evaluations of commercial speed monitoring devices, and major themes and issues identified during the focus group. The in-vehicle study allowed for a careful examination of driving behavior in the presence and absence of a speed monitoring and warning device among chronic speeders. In addition, certain subjective data was gathered to access participants' experiences with the device and their overall acceptance of the system during device removal.

Based on findings from the focus groups, the procedures implemented placed minimal demands on the participants, once the system was installed. In order to promote recruitment, cooperation, and retention, the emphasis in the study design was automated data collection. Data collection did not require trip logs, travel diaries, or active requirements for data downloads.

\subsection{Study Design}

The study used a mixed factorial design, with the treatment phase as a within-subjects factor and age (e.g., 21 to 29, $\geq 30$ ) and gender as between subjects factors. While type of residence area of the participant (urban, suburban, rural) may play a role in speeding, as would a variety of other factors (e.g., vehicle characteristics, other demographic characteristics, commuter patterns, fuel prices, local enforcement practices, roadway network characteristics), adding such additional variables to the study design could increase the size of the sample or decrease the cell size, in addition to complicating recruiting, and installation. Therefore, for this pilot study, residential area type was not included as a factor in the research design.

The within-subjects factor of the treatment phase had three levels: baseline; treatment; and followup. The pilot was not intended to fully quantify the magnitude and temporal aspects of the treatment. However, to avoid mistaking gradual effects for the absence of treatment effects, the study design employed an eight week data collection period for each participant. This includes a two-week baseline period, a four-week treatment period, and a two-week follow-up period. Although this design would be too limited for a full-blown assessment, it was considered to be adequate to meet the requirements of this pilot.

In addition to this formal aspect of the design, a few participants continued with the treatment for an extended period. Five participants experienced a treatment period of eight weeks and a follow-up period of four weeks. While this small sample was not expected to provide meaningful statistical treatment, it may provide some insight into the robustness of effects and should inform the planning of any subsequent full-scale evaluation programs of this type.

\subsection{Participant Recruitment}

All participants were recruited from the Maryland suburbs of Washington, DC. Recruitment targeted people over 21 years old, in possession of a valid driver's license, who drove a passenger vehicle on a regular basis at least 100 miles per average week. All participants were required to have received at least three speeding violations within the past three years.

Finding such drivers among a population of drivers within a limited geographic area was a challenge. Two recruitment strategies were explored in order to minimize cost and maximize the potential of 
identifying and recruiting this challenging population. The first method attempted to engage insurance companies, and request their assistance in identifying and recruiting potential participants by using the information retained on their policyholders' driver records. Ideally, insurance companies have a vested interest in minimizing crash risk among their clients, and this would provide the incentive needed for these companies to participate in the study. Two insurance companies were approached, and both declined to participate for the following reasons:

- The companies would not provide client information to a third party without the policyholder's consent.

- The electronic records for the policyholder did not specify the type of violation. Accessing this type of information would require manual review of the driver's record which would be costly and time consuming.

- The companies believed that very few of their clients would meet the study criteria.

- The companies did not want to alienate their clients by identifying their violations and flaws.

The second recruitment strategy involved approaching and developing a cooperative agreement with Maryland's Motor Vehicle Administration (MVA) to provide a mechanism for identifying a pool of qualified drivers. Once a working relationship was established, a four-step structured sampling and enrollment strategy was implemented:

- Sampling frame - a well-defined sampling frame of licensed drivers who lived in the state of Maryland and met specified criteria for past speeding citations was provided to the MVA.

- Driver sample - The MVA generated a random driver sample from the frame for recruitment.

- Initial contact - The MVA contacted the driver sample and requested that they contact the research team to discuss participation in a research study. This method preserved the anonymity of the drivers until they elected to participate in the survey.

- Intake survey and recruitment - Once interested drivers contacted the research team, callers were screened to recruit qualified study participants.

In addition to speeding violation history, information on current insurance, current license status, and estimated miles driven in a week was collected during the intake screener. All participants were required to meet the study criteria regarding weekly miles traveled and violations. The screener also asked several questions about driving style and attitudes, as well as certain demographic data (e.g., gender, age range) which was useful for insuring a reasonable distribution of these variables in the final set of participants. Eligible participants were informed that they would be contacted later to schedule a date to install the speed monitoring and feedback device.

\subsubsection{Participant Sample}

Based on the MVA driver records, 9,304 licensed drivers residing in six counties of Maryland met the initial (speeding violation) and age criteria. The counties included: Montgomery, Howard, Prince George, Frederick, and Carroll (see Table 1). The Maryland MVA sent recruitment letters to 6,361 individuals. Of those, 271 individuals contacted the research team, and 183 agreed to complete a screener after hearing a brief description of the study. 


\begin{tabular}{|l|c|c|c|}
\hline \multicolumn{1}{|c|}{ County } & \multicolumn{3}{c|}{ Eligible Drivers } \\
\hline & Male & Female & Total \\
\hline Montgomery & 3,406 & 994 & 4,400 \\
\hline Prince George's & 1,214 & 437 & 1,651 \\
\hline Howard & 471 & 168 & 639 \\
\hline Anne Arundal & 1,020 & 373 & 1,393 \\
\hline Carroll & 318 & 145 & 463 \\
\hline Frederick & 546 & 212 & 758 \\
\hline
\end{tabular}

\section{Table 1: Maryland counties included in participant recruitment}

A total of 101 participants were enrolled in the study and had tiwiPro units installed in their vehicles. However, data from 18 participants was compromised and their data needed to be replaced. Participants were removed from the study for a variety of reasons which included: travelling out of state for work (not using their own vehicle); driving status change (license revocation); vehicle flooded; tampering with the device; and vehicle was involved in a crash shortly after going into the treatment phase. It is important to note that the participant involved in the crash reported that it was unrelated to the presence of the warning system.

Eighty-three participants were enrolled and provided usable driving data. Seventy-eight were enrolled in the short duration treatment condition, and 5 in the longer duration treatment condition. The age and gender distribution is provided in Table 2.

\begin{tabular}{|l|l|l|}
\hline & $\mathbf{2 1 - 2 9}$ Years Old & $\mathbf{3 0}+$ Years Old \\
\hline Female & 19 & 22 \\
\hline Male & 20 & 22 \\
\hline
\end{tabular}

\section{Table 2: Age and gender distribution of participants}

All of the participants were the sole driver of their vehicle. Eighty-one participants $(97 \%)$ drove their vehicle almost every day, and eighty participants (96\%) drove at least 100 miles in an average week. While participants were sent letters from the MVA because their driving record indicated that they had received at least 3 speeding violations within the past three years, when asked to report the number of speeding violations they had received, only 68 participants $(82 \%)$ admitted to receiving 3 or more violation in the past three years. Fourteen percent reported receiving only two within the same time.

It is important to note that the research team elected not to include teens in this study, for a number of reasons. As part of the research design, drivers were required to meet a minimum driving criteria (e.g., at least 100 miles per average week) and accumulate 3 or more speeding citations during the past 3 years. It would be challenging to identify fully licensed young drivers age 15 - 20 who would meet the criteria outlined above, by driving at least 100 miles in a week and having accumulated 3, or more speeding violations. In Maryland, in order to obtain and retain a graduated driver's license, a teen must be at least 16 years and 6 months old. Under a provisional license in Maryland's graduated 
driver's licensing program, a driver with a speeding ticket (or any other "Moving violation") resets the clock on the18-month provisional period, and also requires the driver to take a driver improvement class, if it's a first offense. If there is a second offense during provisional period, the driver's license will be suspended for 30 days, and third offense can be 180-day suspension or full revocation and restart the 18 month provisional period.

In addition, including teens younger than 18 years as part of the target population would have complicated the recruiting process. Both parental consent and teen assent would have been required. This criterion would likely have increased the number of drop-outs. That is, if one or the other party no longer agreed to participate in the study, the system would have had to be removed from their vehicle. Increasing the number of drop-outs would have increased the number of persons with incomplete data for the study and/or prolong the recruitment process as well as the study duration while replacements were sought.

\subsection{Data Collection Procedures}

The data collection consisted of four stages: (1) participant screening; (2) device installation; (3) data collection; (4) device removal and debrief. Participant screening is described above (see Section 4.2.3). The following sections outline the three remaining stages in detail.

\subsubsection{Device Installation}

Once the participant provided informed consent, the device was installed in the participant's vehicle. The device installation was quick and straightforward, lasting approximately 15 to 20 minutes. The system was connected to the OBD connector in the vehicle and attached to the left corner of the windshield. During the testing, it was noted that the red LED light would come on during the baseline data collection (when the verbal alert was not activated). In addition, it was noted that the red LED would turn on prior to the driver receiving a verbal alert during the treatment phase. The researchers were concerned that the drivers might learn that the red LED was linked to a driving speed. So in order to prevent the driver from using the LED to predict when they would be receiving a verbal alert during treatment or use it to guide their speed during the baseline and followup phase, the LED was covered so that drivers was unaware of its presence or meaning.

Once the device was physically attached to the vehicle, the technician calibrated and activated the device for data collection. Just prior to leaving the installation appointment, participants were familiarized with the operation of the device, the kind of warnings they should expect, who to contact in the event of an emergency or crash, or if the device became dislodged from the windshield or OBD connector. All participants were given contact information for a technician who was on call (24 hours/day) for the duration of the study, as well as a reminder card with the information regarding their scheduled removal date.

\subsubsection{Data Collection}

Once the participant was enrolled in the study and the feedback device was installed in their vehicle, data collection proceeded with minimal requirements on the part of the participant. The device allowed automated downloading from the inthinc servers. The research team developed quality control procedures which involved monitoring data routinely to confirm that the devices were operational, the vehicles were being driven regularly, and the data did not appear aberrant. Once 
enrolled, all participants experienced a baseline phase lasting approximately two weeks. During this time, the device collected baseline data without providing speeding feedback to the driver.

Normally, the data collected with the tiwiPro is available only from inthinc's user portal as an eventbased interactive reporting system. The system reports trips and violations of pre-defined thresholds. For this effort, inthinc provided "bread crumb" data. This is a more continuous stream of travel and speed data, which includes the events (speeding violation, hard decelerations, etc.). Data was delivered to an FTP server that the research team was able to access for downloads on a daily basis. These data were appended to a SAS dataset and joined with demographic data collected when the participant was screened and enrolled in the study.

Each day's file contained all the data for all the participants who had driven on that day. Each record in the dataset was marked with the participant ID, the date and time, location (lat/long), speed, speed limit, incremental time, incremental distance, and event type. Although most of these are selfexplanatory, the event type was somewhat more complex.

In general, the event type was listed as "Location," indicating that the data for that record was simply a tally of the time and distance traveled since the last record. When the driver was above the threshold for speeding in any given posted speed limit category, an indication of "Speeding" was listed instead of "Location" for event type. This would allow the calculation of proportion of miles traveled while speeding relative to the total miles traveled for each trip for each participant. An event type of "Speeding" did not indicate that verbal feedback was being provided, just that they were travelling at a speed that was greater than $8 \mathrm{mph}$ (our preset threshold) ${ }^{1}$ above the posted speed limit. For other records, event type was identified as "Speed Coaching," indicating that verbal feedback was delivered to the driver at that point. "Speed Coaching" only occurred during the treatment phase of the study.

Data from the inthinc portal and FTP data file were monitored daily to identify any anomalies or suspicious driving behavior. If a participant's driving data did not appear on the portal or in the file for more than 24 hours, the participant was contacted to confirm that the individual was actively driving and whether or not the device was still activated. If the participant had not been driving for several days, the duration of any of the phases was extended to achieve sufficient travel speed and exposure data.

Approximately two weeks after installation, the treatment phase was activated for each participant. Activation was executed remotely, and involved no action by the participant. This one operation required communication between the research team and inthinc personnel. During the treatment phase, the participant would trigger a verbal alert if their speed was at least $8 \mathrm{mph}$ over the posted speed limit for a given roadway. Participants were informed in advance of the date of the feedback mode changes. The research team elected to adopt this strategy in order to avoid startling the participant and inadvertently causing a reaction that might have resulted in an injury or crash. While most participants experienced a treatment phase for 4 weeks (short duration), 5 participants experienced an 8-week treatment phase (longer duration).

\footnotetext{
${ }^{1}$ For the purposes of this study, the preset threshold for a speeding warning was set at greater than 8 mph over the posted speed limit to help prevent participants' egregious speeding. Note: NHTSA does not condone driving above the posted speed limit. Driving over the posted speed limit is against the law.
} 
During the treatment phase, participants were instructed to contact the research team if they noticed that the verbal alert was triggered on a given roadway when they were not travelling over the posted speed limit. Inthinc encourages updates to their speed limit database and, in order to increase the likelihood of participant acceptance of this kind of device, the research team wanted to limit the number of false alarms experienced by participants. Once notified by the subject, the research team would confirm the information, and contact inthinc with the requested update. Several participants opted to report a discrepancy to the research team, and the information was confirmed and reported to inthinc. These notifications occurred only twice and the steps to rectify them were accomplished immediately to minimize any data impact. Although there is the potential to have some records in the database that were subject to the outcomes of these erroneous speed limits, the quantity and impact was likely limited.

Following the treatment phase, the verbal alerts were silenced remotely for the duration of the study. As with the treatment phase, participants were notified when the phase was changed, and the duration of the follow-up phase varied by participant. Short duration participants experienced a 2week follow-up phase, while long-duration participants experienced 4 weeks of follow-up.

\subsubsection{Device Removal and Debrief}

At the completion of data collection, each participant was scheduled for device removal from their vehicle and debriefing. The removal of the device from the vehicle took approximately 5 minutes. The debriefing covered topics such as effectiveness of the device, acceptability, motivation, perceived changes in behavior, and so forth. Feasibility measures are discussed further below. Upon completion of the study, participants received $\$ 150$ for their participation.

\subsection{Data Cleaning}

During the course of the study, data cleaning involved value transformations, variable derivations, exclusion of erroneous data, elimination of useless records, and identification of tampering situations. In addition, several variables were derived to allow categorizations for the data analysis. The most salient derivations and steps performed during the data cleaning are described below.

Individual trips were defined for each participant. The beginning of a trip start was identified by looking at either the first reported record or by a record with the description "Ignition On." The end of a trip end was identified by a record with the description "Ignition Off." If an individual trip had fewer than 3 records, or an elapsed time of zero minutes, a trip length of zero miles, or a trip of duration of over 10 hours, records in that trip were excluded. This represented less than one percent of all the trips. Given that trips were defined by the time/distance between an "Ignition On" flag and an "Ignition Off' flag, it was highly unlikely that a driver would travel for 10 consecutive hours without taking a break (e.g. refuel, stretch legs) which would require them to turn off the vehicle. Thus any single trip with a duration of more than 10 hours was viewed as suspect and removed from the data. Once trips were identified, trip distances, times, and the number of records making up a trip were calculated.

Occasionally, faulty GPS data were identified. Latitude or longitude would freeze, giving multiple adjacent records with identical values for one, the other, or both variables. If more than 5 consecutive records with faulty GPS data were identified, those records were excluded. This was not a large proportion (less than 1 percent) of the dataset, but there were some cases. In addition, some 
records did not have good position information (less than 1 percent). Also, parking in an underground parking garage was likely to result in the GPS losing its lock for the next trip. After cycling the ignition, the system would reset itself, but the trip immediately following the underground garage was typically plagued with bad GPS data.

Data was inspected for extremely high speeds (e.g., over $100 \mathrm{mph}$ ), but no records were identified.

Speed limit data was examined for strange values. To minimize false alarms caused by intersections and interchanges, inthinc defined intersection speed limits as $255 \mathrm{mph}$ and interchange ramp speed limits as $78 \mathrm{mph}$. As such, records related to these situations typically were excluded.

There were 4 cases of tampering. There is a tampering indication in the raw data file that indicates when the device was unplugged from the OBD port. In some cases, trips terminated abruptly in the midst of a journey and then resumed at a later time and a different location. Other cases simply ended at one location and then started the subsequent trip at a different location. Each of these situations caused the integrity of the participant's data to be suspect. Chronic tampering ultimately resulted in removal of that participant from the study and their data from the dataset. Five participants decided that they wanted to leave prior to completion of the study.

The tiwiPro device performs periodic data collection on the location and speed of the vehicle in which they are installed. Although usually reported every few seconds, the periods were not of a consistent temporal duration, nor did they occur after some distance had been traveled since the last update. As such, it was impossible to treat them as uniform during the data analysis. Instead, they required us to sum the distances (our primary unit of measure for computing rates of behavior). The analysis reported here examines the sum of distance traveled while speeding per trip in relation to total distance traveled per trip in each of the study phases. This complicated the analysis somewhat, requiring the use of a mixed model analysis rather than a simple ANOVA or MANOVA, but still allowed a closer examination at the mile by mile behavior of drivers as they made various types of trips on various types of roads.

Several variables were created to characterize the data and assist with the subsequent analysis. Atspeed records were defined as a subset of the overall dataset. At-speed (@speed) records were defined as those records where the driver was traveling not less than $15 \mathrm{mph}$ below the posted speed limit (See Figure 2). It was assumed that the speed data for these records suggested that participants had the opportunity to speed. That is, drivers were not experiencing severe congestion, stopped (or idling), or in the stages of early acceleration just after a stop. Speeds below this limit might indicate that the drivers speed was not selected, but impeded. However, because there was no way to have any information on the surrounding traffic stream, there was no way to confirm this. 


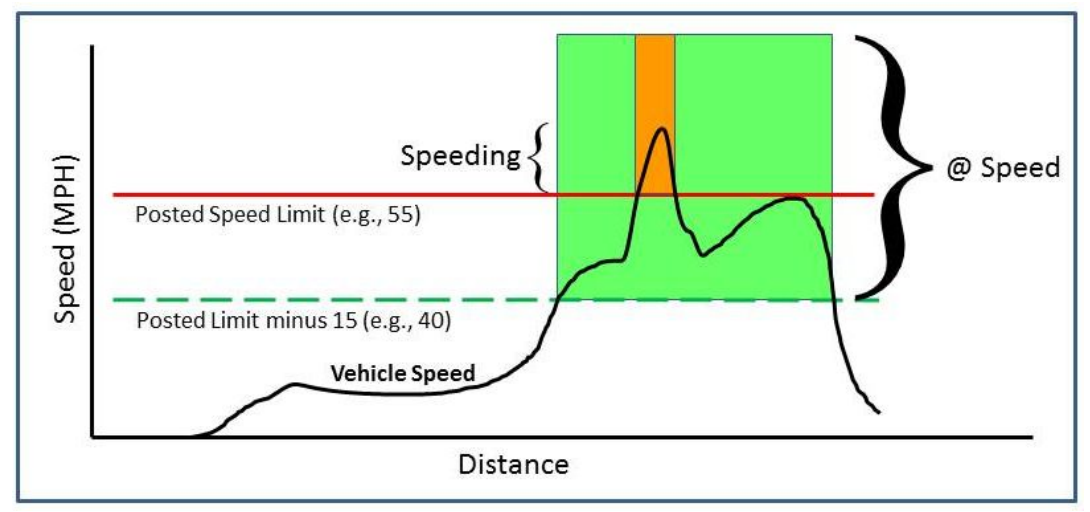

Figure 2: Visual representation of at-speed

Since trips had been identified using raw data records, it was then possible to use only the at-speed records for a given trip to calculate within trip statistics of speeding incidence. All of the statistics presented in this report have been created using this subset of the overall dataset.

Finally, habitual speeders were defined as participants who drove more than 30 percent of their total miles traveled speeding $8 \mathrm{mph}$ over the posted speed limit during the baseline phase. These participants may be more willing to risk receiving a speeding violation than those drivers who were speeding but did not travel above the $8 \mathrm{mph}$ threshold. The most frequent speeders reached approximately 60 percent of their total miles travelling $8 \mathrm{mph}$ over the posted speed limit.

At the conclusion of the study, the data file contained 2,475,760 records. These represent periodic position and speed data collected every few seconds. Once the file was cleaned and all unusable records were removed, 2,067,529 records remained. 1,434,807 of these records were at-speed, and these records represented 29,086 trips (285,100 miles). Eighty-five percent of all the at-speed records contained at least one speeding event associated with it.

\begin{tabular}{|c|c|c|c|}
\hline & Observations & Trips & Miles \\
\hline Raw Data & $2,475,760$ & 37,871 & $353,165.86$ \\
\hline $\begin{array}{c}\text { GPS Locked } \\
\text { Data }\end{array}$ & $2,457,346$ & 37,843 & $353,118.97$ \\
\hline Cleaned Data & $2,067,529$ & 32,075 & $299,156.65$ \\
\hline At-Speed Data & $1,434,807$ & 29,086 & $285,100.33$ \\
\hline
\end{tabular}

Table 3: Record Counts for Analysis

\section{Results}

It is important to note that the intent of this study was to explore driver monitoring warning systems in terms of their ability to monitor and reduce speeding behavior among adult drivers with a history of speeding violations. It was not intended to examine its effects on speeding related to specific speed zones or speed limits. One type of measure of the effectiveness of this type of warning system 
is the percent of travel occurring at a given number of miles per hour above the posted speed when the alerts are activated relative to when the alerts are silenced.

The following sections outline the overall effects of the speed monitoring/warning systems on four different types of speeding behavior.

- $\quad$ Driving over the speed limit-- Captures events when participants are driving at any speed above the posted speed limit.

- $\quad$ Driving up to $8 \mathrm{mph}$ over the posted speed limit - Captures events when participants are driving at a speed that is above the posted speed limit, but below the threshold set for receiving alerts during the treatment phase.

- Driving above $8 \mathrm{mph}$ over the speed limit - Captures events when participants are driving at a speed that is above the threshold set for receiving alerts during the treatment phase.

- $\quad$ Driving at speeds above $20 \mathrm{mph}$ over the posted speed limit- The $20 \mathrm{mph}$ limit was selected because it captures events when the participant's absolute speed is in a category that is well above most typical driving speeds, and can be clearly characterized as aggressive driving, therefore $20 \mathrm{mph}$ was chosen as a conservative estimate of aggressive speeding.

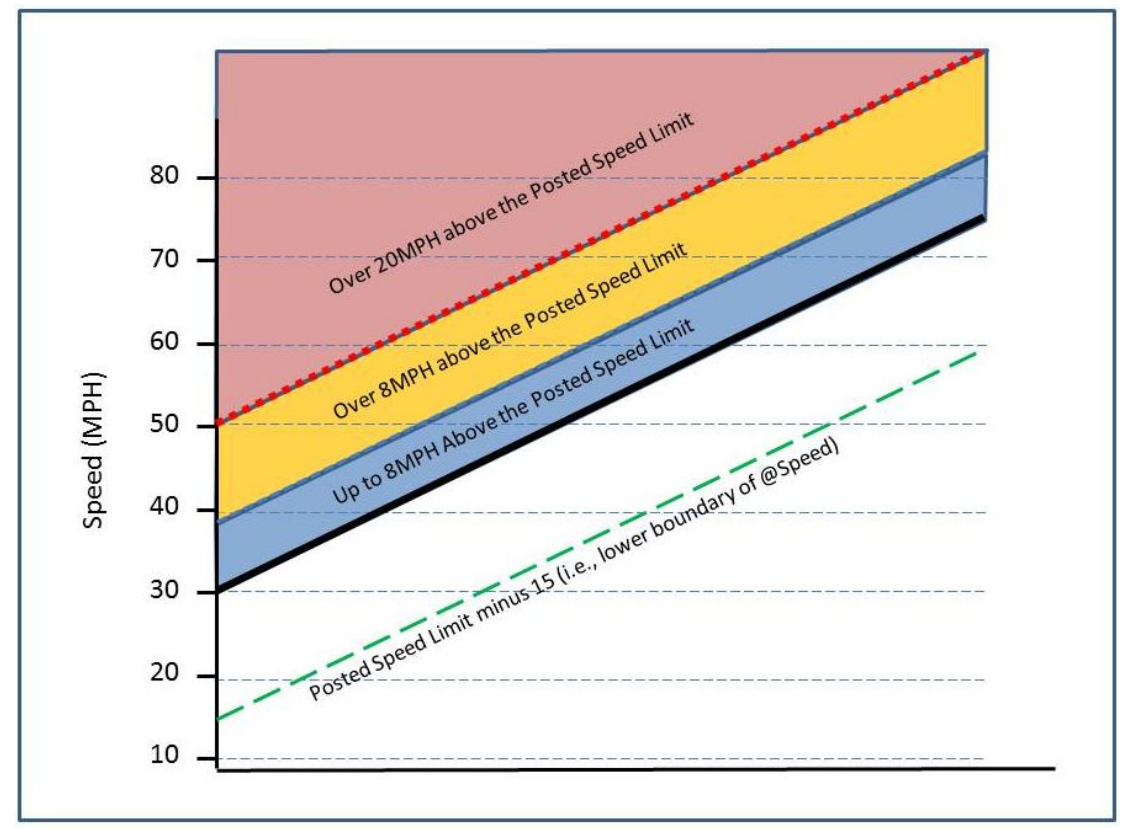

\section{Figure 3. Graphical depiction of speeding behavior measures}

The data used in this analysis was distance based rather than time based. That is, the proportion of trip distance traveled over a posted speed limit in relation to the total trip miles traveled. While timebased data was considered, it would complicate the analysis when vehicle speed was very slow (e.g., congestion) or zero (e.g., idling). 
The following analyses were performed using a mixed model approach analyzing logit transformed proportional data. There were three general approach options - mixed model, repeated measures, or logistic regression. Logistic regression is a more powerful choice for binomial data. The current data do not suffer from power constraints and are not binomial (because means are derived from proportions and are continuous), so a logistic regression approach is no longer optimal. The analysis outlined below is a repeated measures or mixed model. It is a more appropriate approach, which is also more commonly used in this domain.

Instead of using the traditional repeated measures ANOVA approach, the following data were analyzed using a mixed model approach with SAS PROC MIXED. SAS PROC MIXED was more appropriate for the data structure and questions of interest, in addition to having advantages over traditional repeated measures approaches. The advantages of this approach over traditional repeated measures are outlined in Appendix A for interested readers. In addition, the dependent variables of interest were subjected to a logit transform, instead of the more common arcsin transform approach. The reasons for this step and background assumptions are also presented in Appendix A.

SAS PROC MIXED was used for the following repeated measures analyses on the logit transform of each variable (i.e., the average proportion traveling over the posted speed limit; up to $8 \mathrm{mph}$ above the speed limit, over $8 \mathrm{mph}$ above the posted speed limit, and over $20 \mathrm{mph}$ above the posted speed limit), with an ante-dependence covariance structure. All dependent variables discussed below were analyzed as logit transforms of the original dependent variable. In addition, the p values reported for contrast comparisons with t-tests are Sidak adjusted. Note that treatment phase and road type were within-subjects variables. Appendix A provides further explanation of these approaches.

There are several things to note about the following analyses. Because this is an exploration of speeding behavior, these analyses focus only on cases where there is an opportunity to speed; that is, when the driver was traveling at a speed not less than 15 miles of the posted speed limit or at-speed. Also, age was separated into two broad categories-drivers 21 to 29 years old and those who were 30 or older. It is also important to note that there were no main effects or interactions with gender, so it is not included in analytical models for increased power.

\subsection{Short Duration Participants}

The following discussion addresses the 78 participants who were enrolled in the short treatment condition. For participants enrolled in the short treatment condition, there was a two week baseline period, a treatment period when the system only provided the driver with verbal alerts of speeding behavior for approximately four weeks, and a follow-up period, which lasted approximately two weeks with no feedback for speeding.

\subsubsection{Driving Over the Speed Limit}

The following sections used " $F$ " and " $\mathrm{t}$ " test statistics to determine the effectiveness of the speed monitoring system on changing the driver's behavior. For those not familiar with these approaches, there are several things to keep in mind. In very general terms, these are numerical outcomes of testing a null hypothesis against an $\mathrm{F}$ or a t distribution to determine whether the data could have 
happened by chance. Note that the null hypothesis is usually that there is no difference between two groups. "F" values are from an F-test, which is the ratio of two sources of variability (within group and between group variability). The " $t$ " values follow a similar logic, except that the value is derived from comparing the sample mean to the sample size, along with the standard deviation. It is derived from a t-test, which is a statistic that compares the null hypothesis to the t-distribution. In both cases, higher numbers indicate a lower likelihood the null hypothesis is true (note that values less than 1 indicate one cannot reject the null hypothesis). Second, in a very basic sense, $\mathrm{p}$ values correspond to how likely the data are to have occurred by chance, assuming the null hypotheses was true. The smaller the p-value number, the less likely data occurred by chance.

Speeding was simply defined as traveling over the posted speed limit for the roadway. Overall, there was a strong effect of the treatment phase, $\mathrm{F}=8.01, \mathrm{p}<.001$. A higher proportion of speeding occurring during the baseline phase $(\mathrm{X}=.45)$ and the follow-up phase $(\mathrm{X}=.44)$ compared to the treatment phase $(\mathrm{X}=.43$ ) (see Figure 4). Speeding was significantly lower during the treatment phase than in the baseline phase, $\mathrm{t}=3.90, \mathrm{p}<.001$, suggesting that the verbal feedback was effective at mitigating the unwanted speeding behavior.

Interestingly, speeding behavior was not significantly different between the follow-up phase and the treatment phase, $\mathrm{t}<1$. This lack of statistical difference could be an indication that there was not an immediate return to the baseline speeding behavior by participants during the follow-up phase, which for this group of participants lasted 2 weeks.

Age had a significant main effect, $\mathrm{F}=8.28, \mathrm{p}<.01$. Drivers 30 and older had a significantly smaller proportion of speeding than those 21 to 29 in all three phases (see Figure 5). The interaction of age and treatment phase was not significant, $\mathrm{F}<1$.

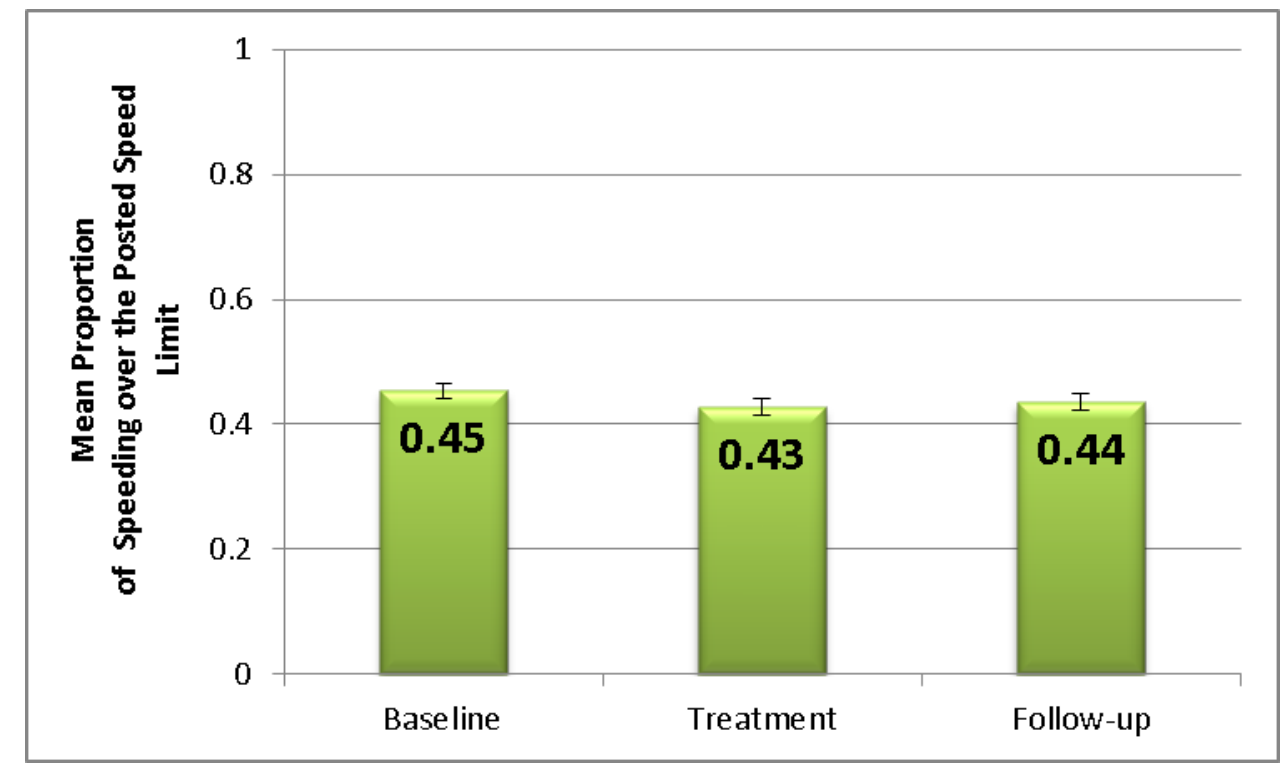

Figure 4. Mean proportion of driving over the posted speed limit for all participants in short condition by phase 


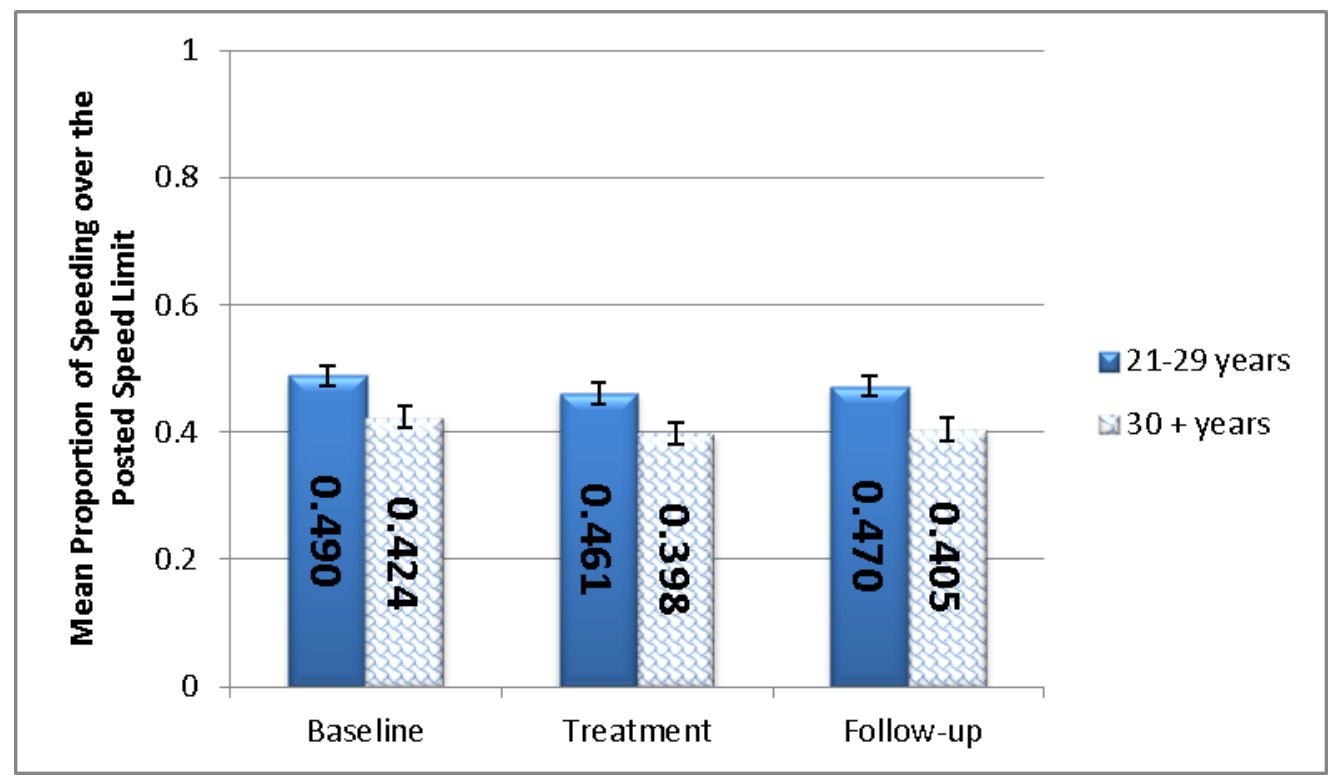

Figure 5. Mean proportion of driving over the posted speed limit for all participants in short condition by age and phase

\subsubsection{Driving up to $8 \mathrm{mph}$ Above the Posted Speed Limit}

During the treatment phase, participants received a verbal alert when their driving speed exceeded the $8 \mathrm{mph}$ over the posted speed limit threshold. If the alert is effective at modifying the participant's behavior, the average proportion of speeding over $8 \mathrm{mph}$ above the posted speed limit is likely to drop off during the treatment phase, suggesting that the drivers respond to the alert by slowing their speed to a level below the alert threshold. Conversely, the average proportion of speeding up to $8 \mathrm{mph}$ above the posted speed limit may escalate as drivers slow down to avoid the alert, but may not slow down to speeds that are below the posted speed limit. This section analyzes the mean proportion of each trip that a participant was speeding up to, but not exceeding, $8 \mathrm{mph}$ over the speed limit in each of the study phases.

There was a robust effect of the treatment phase, $\mathrm{F}=12.17, \mathrm{p}<.0001$. There was an increased proportion of driving up to $8 \mathrm{mph}$ over the posted speed limit for each trip during the treatment phase $(\mathrm{X}=.29)$ when compared to the baseline or follow-up phase $(\mathrm{X}=.27$ and $\mathrm{X}=.28$, respectively) (see Figure 6). Speeding up to $8 \mathrm{mph}$ over the posted speed limit was significantly higher during the treatment phase than during the baseline phase, $\mathrm{t}=-3.72, \mathrm{p}<.005$ or during the follow-up phase, $\mathrm{t}=3.80, \mathrm{p}<.001$. These findings suggest that there was a downward shift in behavior from driving at higher speeds to electing to drive at a speed that is below the threshold for alerts $(8 \mathrm{mph}$ above the posted speed limit) during the treatment phase. Although the participant was still driving over the speed limit, no verbal feedback would have been provided during the treatment phase unless their speed exceeded alert threshold. There was no statistical difference in proportion of speeding up to $8 \mathrm{mph}$ between the baseline and follow-up phases, $\mathrm{t}=<1$, nor was there a significant difference between the two age groups $(F<1)$ (see Figure 7 ), or an interaction of age and treatment phase, $\mathrm{F}=1.13$. 


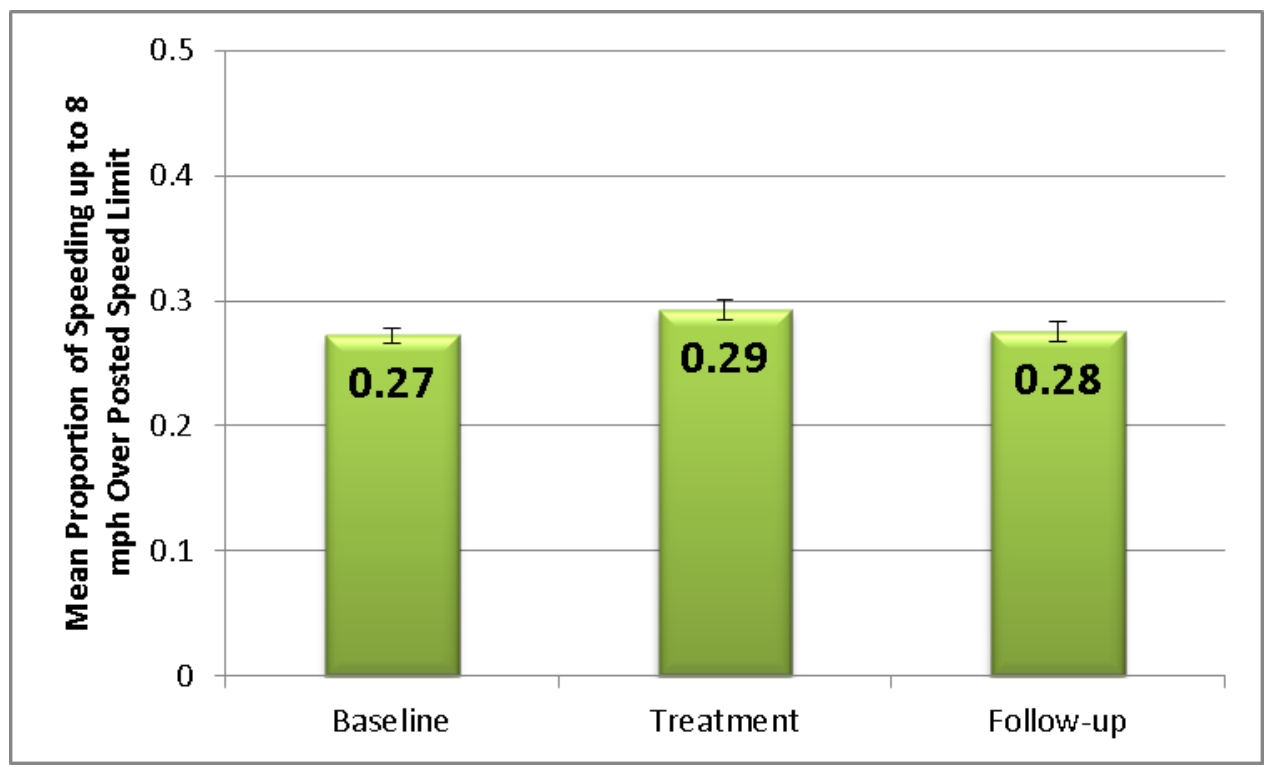

Figure 6. Mean proportion of driving up to $8 \mathrm{mph}$ over the posted speed limit for all participants in short condition

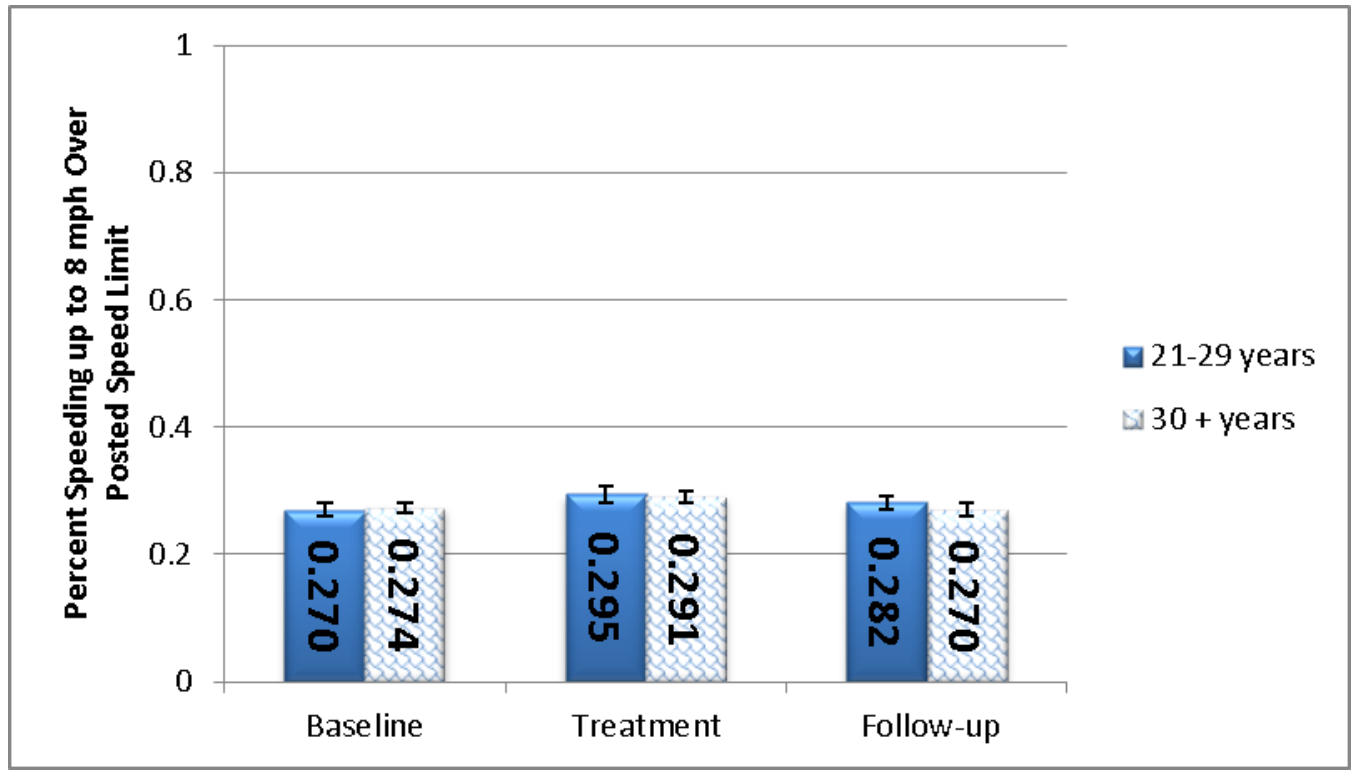

Figure 7. Mean proportion of driving up to $8 \mathrm{mph}$ over the posted speed limit for participants in short condition by age and Phase

\subsubsection{Driving Over $8 \mathrm{mph}$ Above the Posted Speed Limit}

As stated earlier, if the alert received during the treatment phase is effective at modifying the participants' behavior; their average proportion of speeding over $8 \mathrm{mph}$ above the posted speed limit should drop off. This section analyzes the mean proportion for each trip that a participant was speeding more than $8 \mathrm{mph}$ over the speed limit. 
There was a strong effect of the treatment phase, $F=37.84, p<.005$. Speeding over $8 \mathrm{mph}$ was significantly lower during the treatment phase $(\mathrm{X}=.14)$ than during the baseline phase $(\mathrm{X}=.18), \mathrm{t}=$ 7.90, $\mathrm{p}<.0001$ or during the follow-up phase $(\mathrm{X}=.16), \mathrm{t}=-5.89, \mathrm{p}<.0001$. Figure 8 below shows that the speeding behavior decreased dramatically during the treatment phase, suggesting that the alerts do have an influence on suppressing speeding behavior. There was also a significant difference when the baseline and follow-up conditions were examined, $\mathrm{t}=3.18, \mathrm{p}<.01$. Speeding over $8 \mathrm{mph}$ during the follow-up phase was lower than the baseline phase, suggesting that while participants' speeding behavior begins to increase during the 2-week follow-up phase, it does not return to baseline levels immediately.

There was a significant main effect of age, $\mathrm{F}=8.71, \mathrm{p}<.01$, with drivers in the 21-to-29 age group speeding over $8 \mathrm{mph}$ more often than those in the 30+ age group in all three phases (see Figure 9).

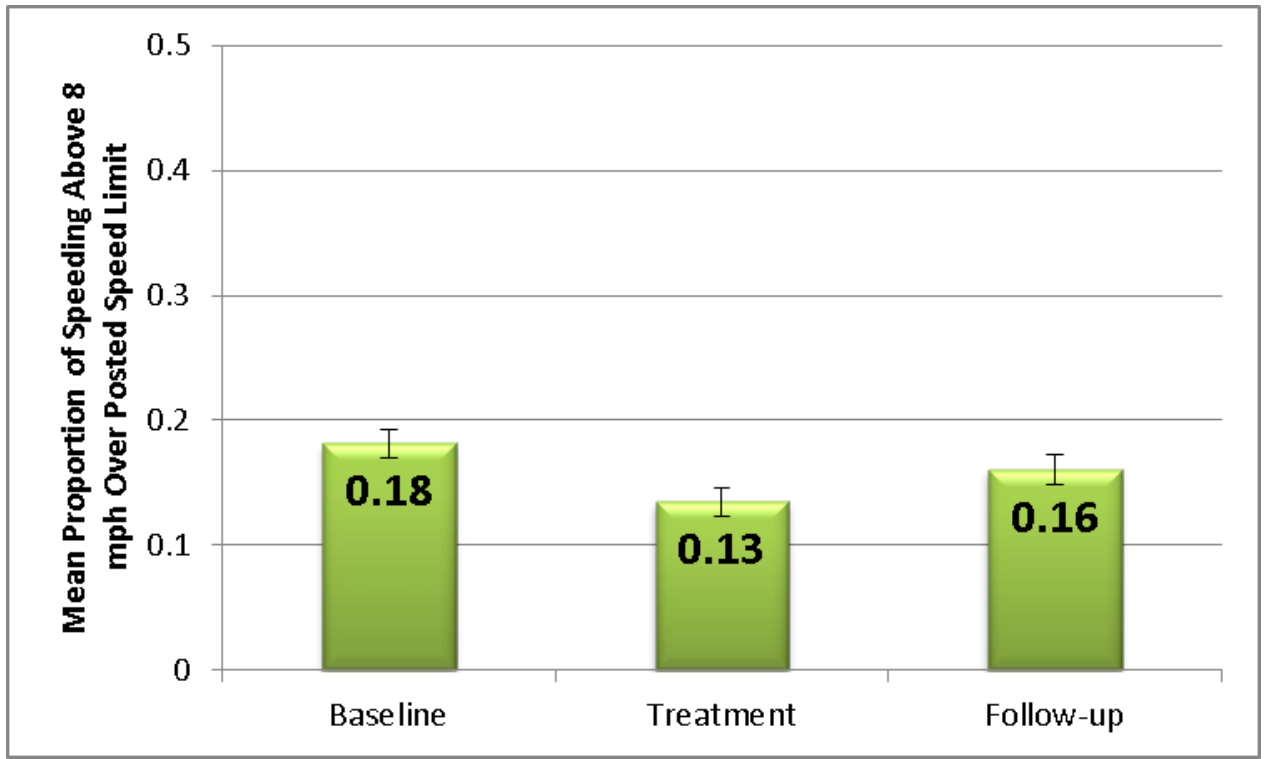

Figure 8. Mean proportion of each trip driving over $8 \mathrm{mph}$ above the posted speed limit for all participants in short condition 


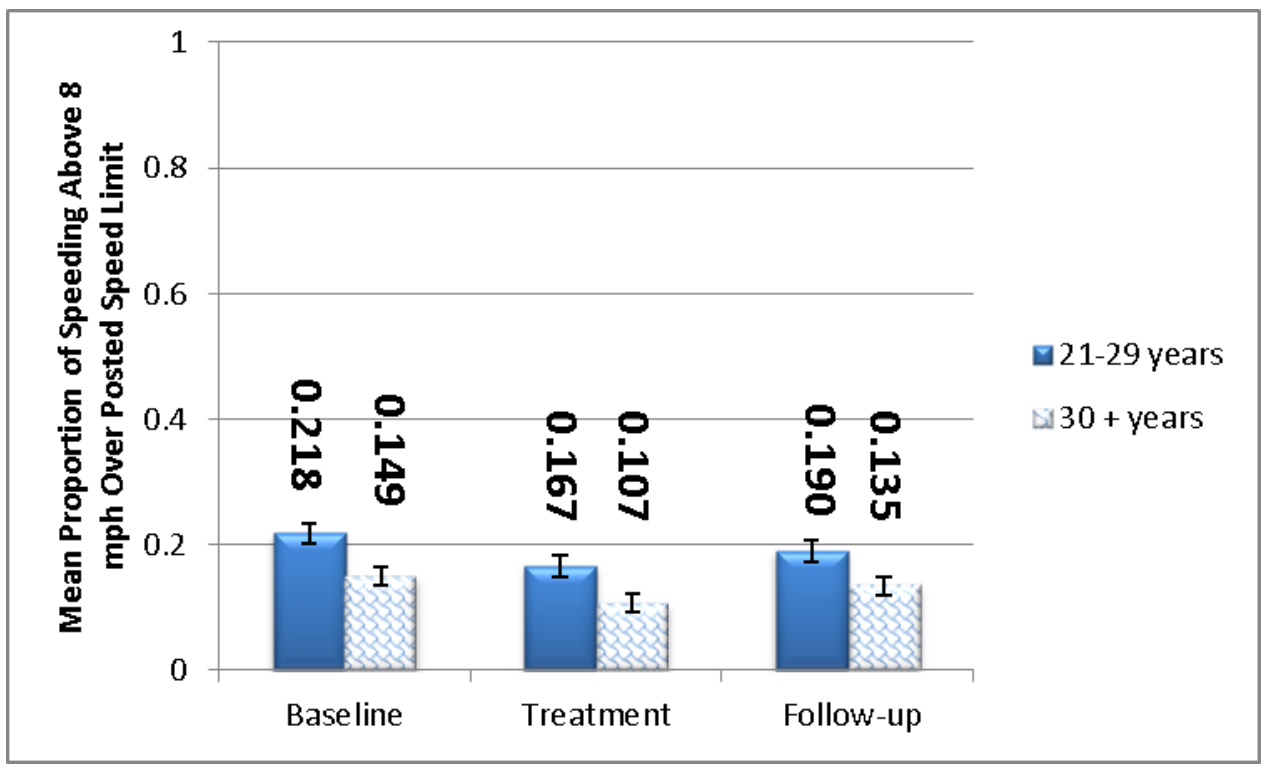

Figure 9. Mean proportion of each trip driving over $8 \mathrm{mph}$ above the posted speed limit for participants in short condition by age and phase

\subsubsection{Driving at Least $20 \mathrm{mph}$ Over the Posted Speed Limit}

When we analyzed the mean proportion of each trip that a participant was speeding at least $20 \mathrm{mph}$ over the posted speed limit, there was a robust effect of the treatment phase, $F=9.92, p<.0005$. Compared to the baseline $(\mathrm{X}=.026)$ or follow-up phase $(\mathrm{X}=.023)$, a lower proportion of speeding $20 \mathrm{mph}$ over the posted speed limit occurred during the treatment phase $(\mathrm{X}=.018)$, suggesting that the alerts were also effective at curbing the speeding behavior at the highest travel speeds (see Figure 10). Speeding at least $20 \mathrm{mph}$ over the posted speed limit was lower during the treatment phase than during the baseline phase, $\mathrm{t}=4.13, \mathrm{p}<.0005$ or the follow-up phase, $\mathrm{t}=-2.41, \mathrm{p}=.05$. There was no significant difference in speeding at least $20 \mathrm{mph}$ over the posted speed limit in the baseline or follow-up phases, $\mathrm{t}=1.37, \mathrm{p}>.05$. This seems to suggest that, at higher speeds, the effects of the system may not endure once the alert is removed. Drivers $21-29$ were more likely to drive $20 \mathrm{mph}$ over the posted speed limit than drivers $30+, \mathrm{F}=5.99, \mathrm{p}<.05$ (see Figure 11) in all three phases. There was no significant interaction of age and treatment phase, $\mathrm{F}<1$. 


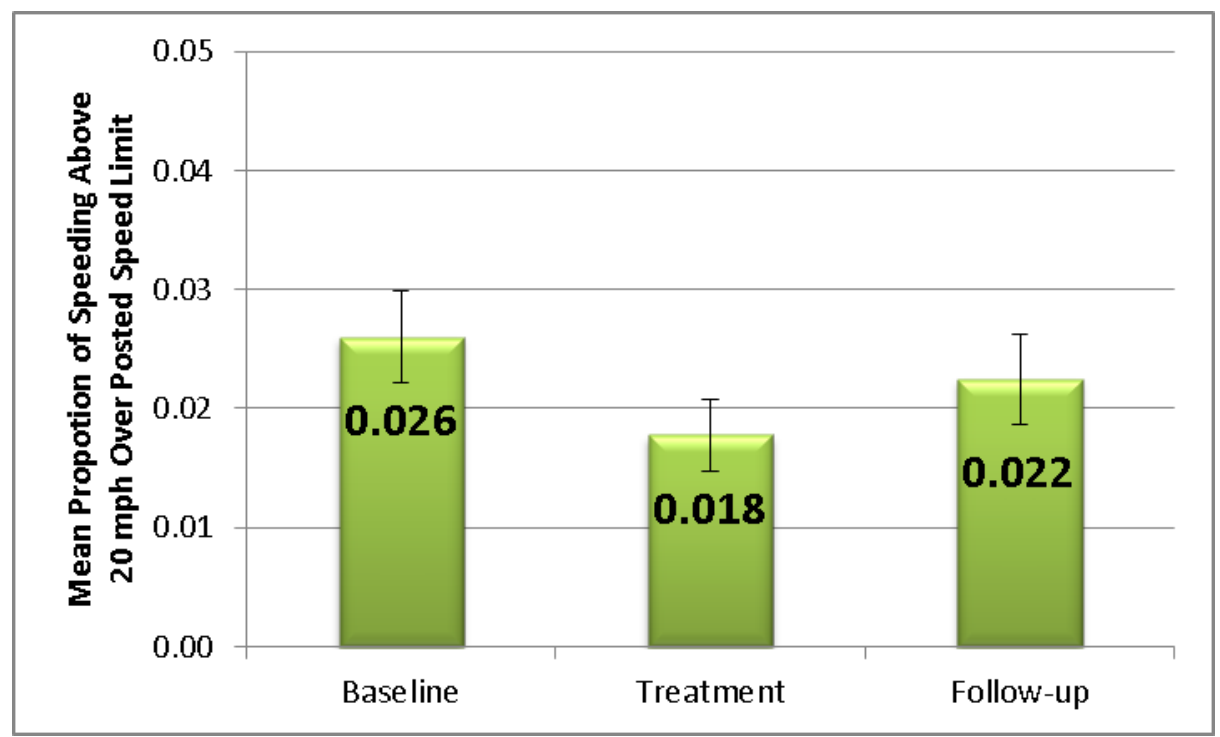

Figure 10. Mean proportion of each trip driving at least $20 \mathrm{mph}$ over the posted speed limit for all participants in short condition

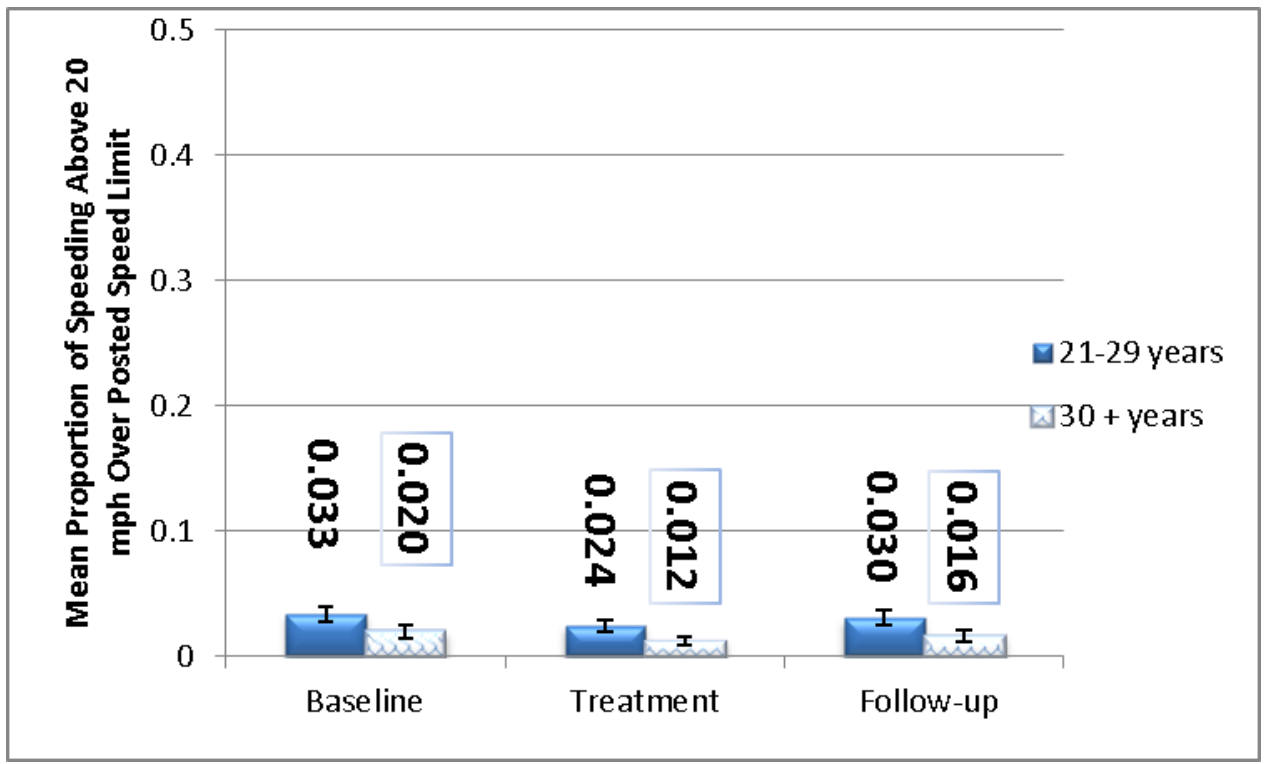

Figure 11. Mean proportion of each trip driving at least $20 \mathrm{mph}$ over the posted speed limit for participants in short condition by age and phase

\subsection{Habitual Versus Nonhabitual Speeders}

For the purposes of this study, habitual speeding was defined as those individuals who drove at least 30 percent of their total miles traveled speeding over $8 \mathrm{mph}$ above the posted speed limit during the baseline phase. Highlighting this group is another way to infer a conservative estimate of the alert's effectiveness. Using this definition, 35 of the 78 short-duration participants were classified as 
habitual speeders and the remaining participants were categorized as nonhabitual speeders. Twentyone of these participants were 21 to 29 years old, and 14 were over 30 years old. Similar to the short duration condition, gender differences were not significant, so data was collapsed for subsequent analyses of habitual speeders. Also, age was not significant throughout, so subsequent analysis was collapsed across age to increase power.

\subsubsection{Habitual Versus Nonhabitual Speeders Driving Over the Speed Limit}

In analyzing the mean proportion of each trip that a habitual speeder was driving over the posted speed limit, we found there was a strong effect of the treatment phase, $F=7.70, p<.005$ (see Figure 12). There was a slight decrease in speeding behavior during the treatment phase $(\mathrm{X}=.43)$, compared to the baseline $(\mathrm{X}=.45), \mathrm{t}=3.83, \mathrm{p}<.001$. There was not a significant difference between the treatment and follow-up $(X=.44), \mathrm{t}=-1.07, \mathrm{p}>.05$. The follow-up phase was significantly different than the baseline, $\mathrm{t}=2.18, \mathrm{p}<.05$.

There was a robust, significant effect of habitual speeding as a category, $F=38.75, \mathrm{p}<.001$. Not surprisingly, habitual speeders had a much higher proportion of speeding than nonhabitual speeders in all three phases (see Figure 13).

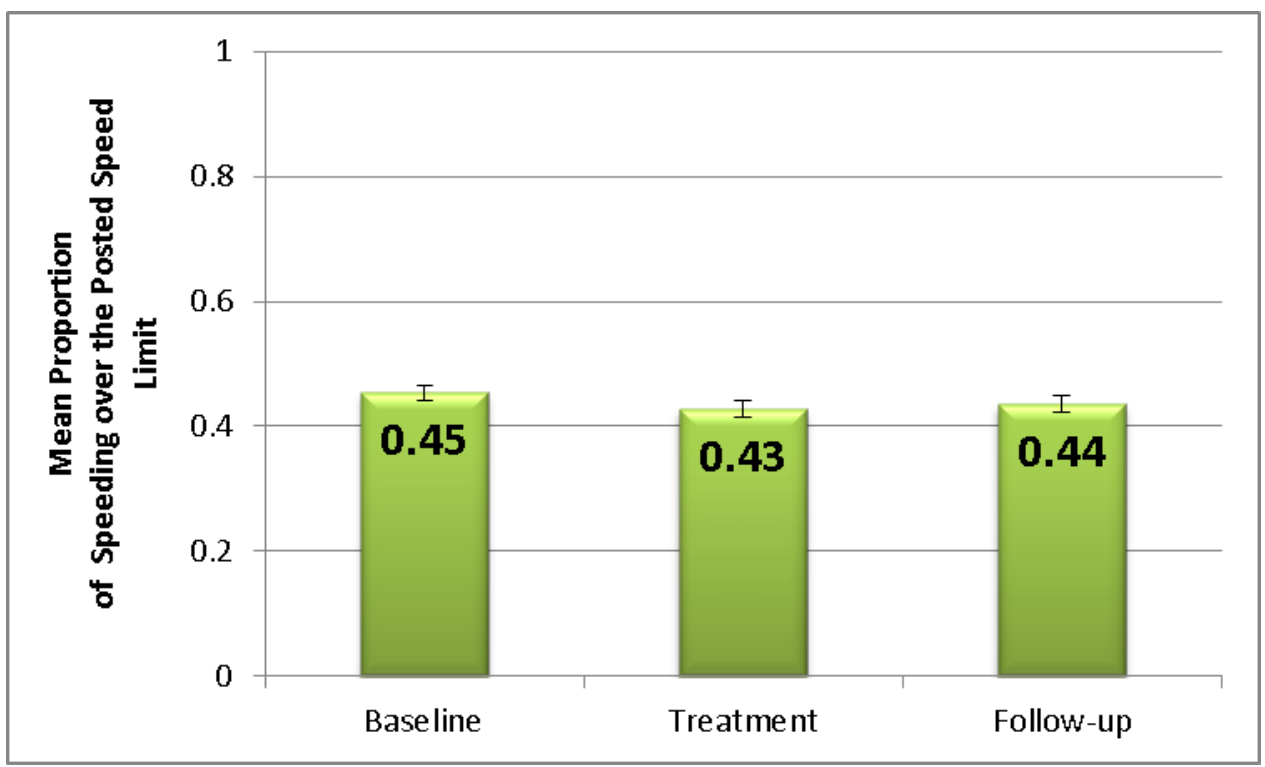

Figure 12. Mean proportion of each trip driving over the posted speed limit for habitual speeders in short condition 


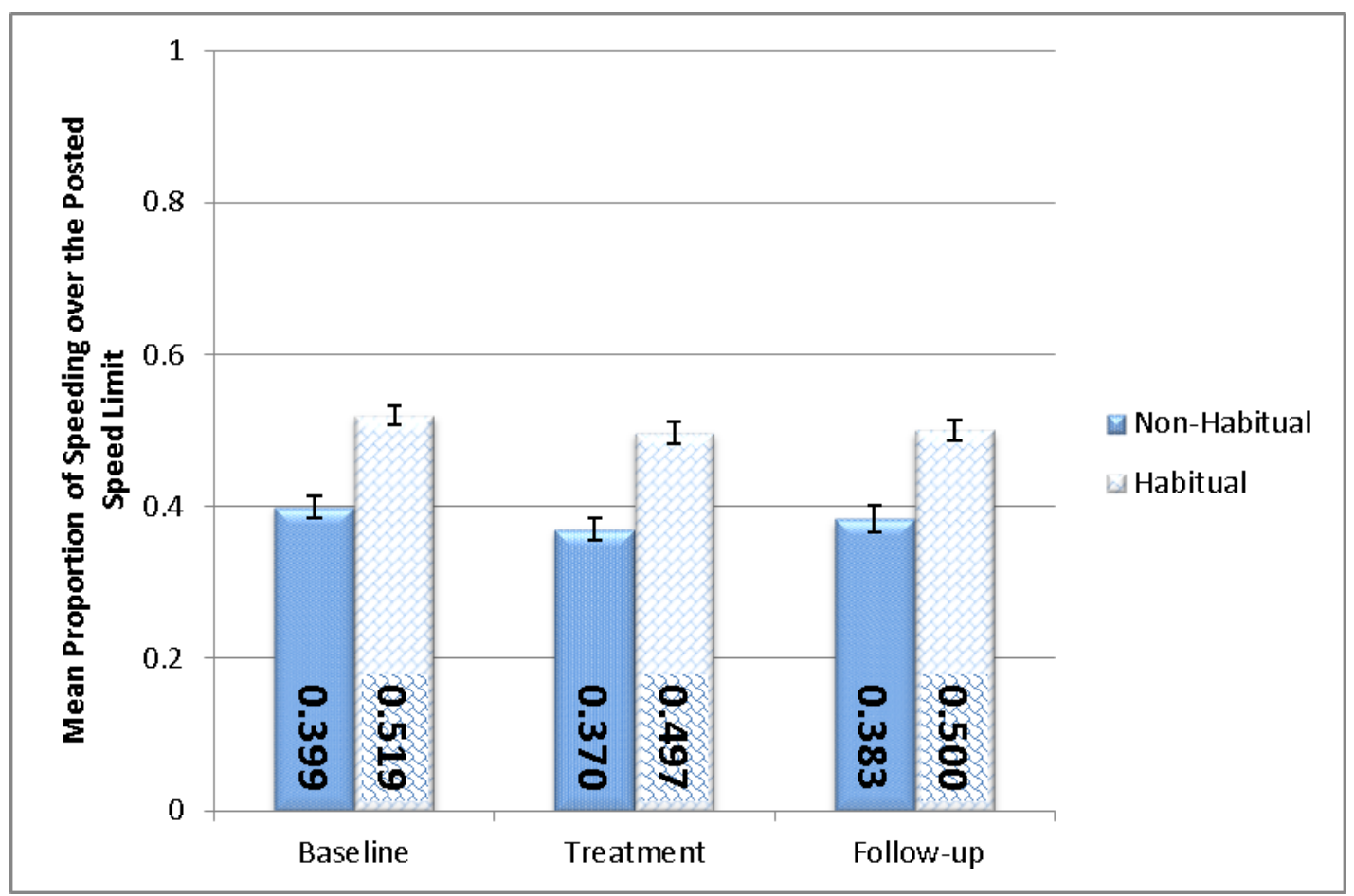

Figure 13. Mean proportion of each trip driving over the posted speed limit for habitual speeders and nonhabitual speeders in short condition by phase

\subsubsection{Habitual Versus Non-habitual Speeders Driving up to $8 \mathrm{mph}$ Above the Posted Speed Limit}

There was a strong main effect of the treatment phase, $\mathrm{F}=13.30, \mathrm{p}<.001$ (see Figure 14). During the treatment phase $(\mathrm{X}=.29)$ there was an increased proportion of speeding up to $8 \mathrm{mph}$ over the speed limit relative to the baseline phase $(\mathrm{X}=.27), \mathrm{t}=-3.99, \mathrm{p}<.001$ or the follow-up phase $(\mathrm{X}=.28), \mathrm{t}=3.96, \mathrm{p}<.001$. There was no statistically significant difference between the baseline and follow-up phases, $\mathrm{t}=-0.36, \mathrm{p}>.05$. The alert seemed to modify the participant's behavior, where the average proportion of speeding up to $8 \mathrm{mph}$ above the posted speed limit escalated as drivers slowed down to avoid the alert.

There was also a significant effect of habitual speeding as a category, $\mathrm{F}=6.05, \mathrm{p}<.05$. Not surprisingly, habitual speeders had a much lower proportion of speeding up to $8 \mathrm{mph}$ than nonhabitual speeders in all three phases (see Figure 15). 


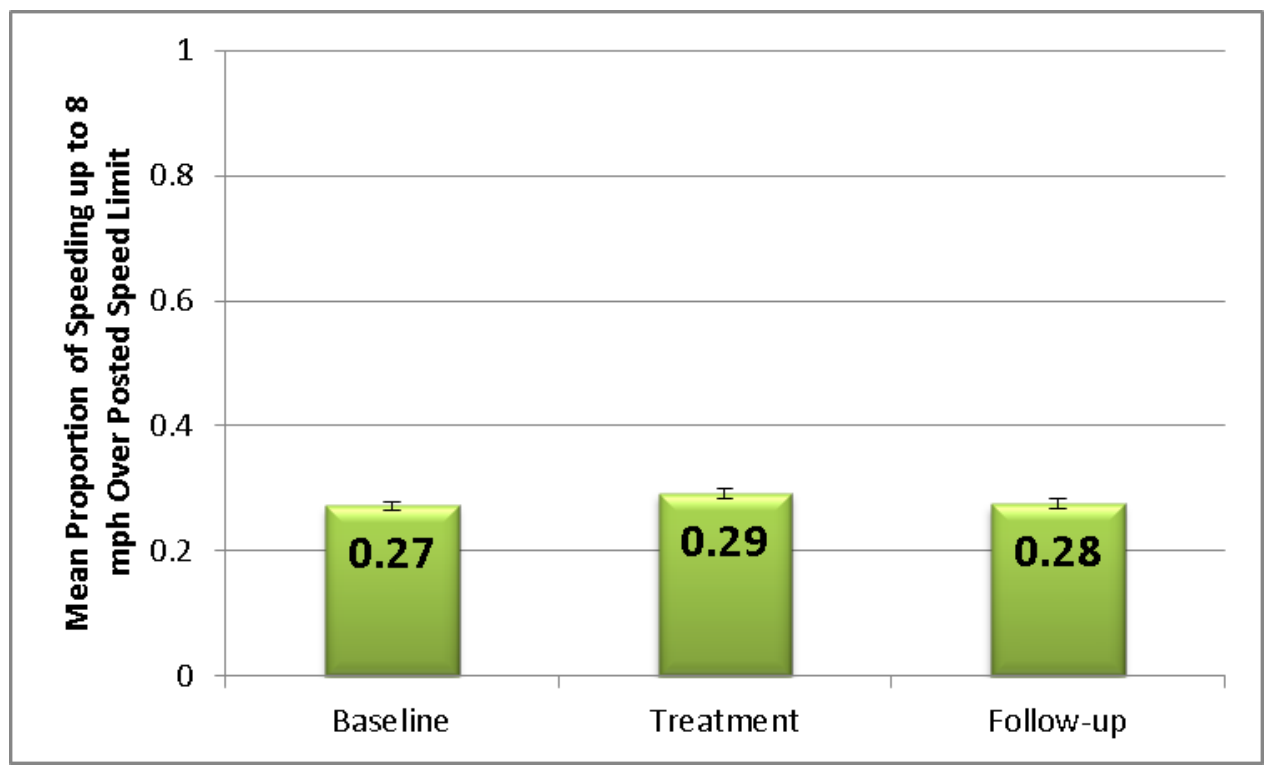

Figure 14. Mean proportion of driving up to $8 \mathrm{mph}$ over the posted speed limit for habitual speeders in short condition

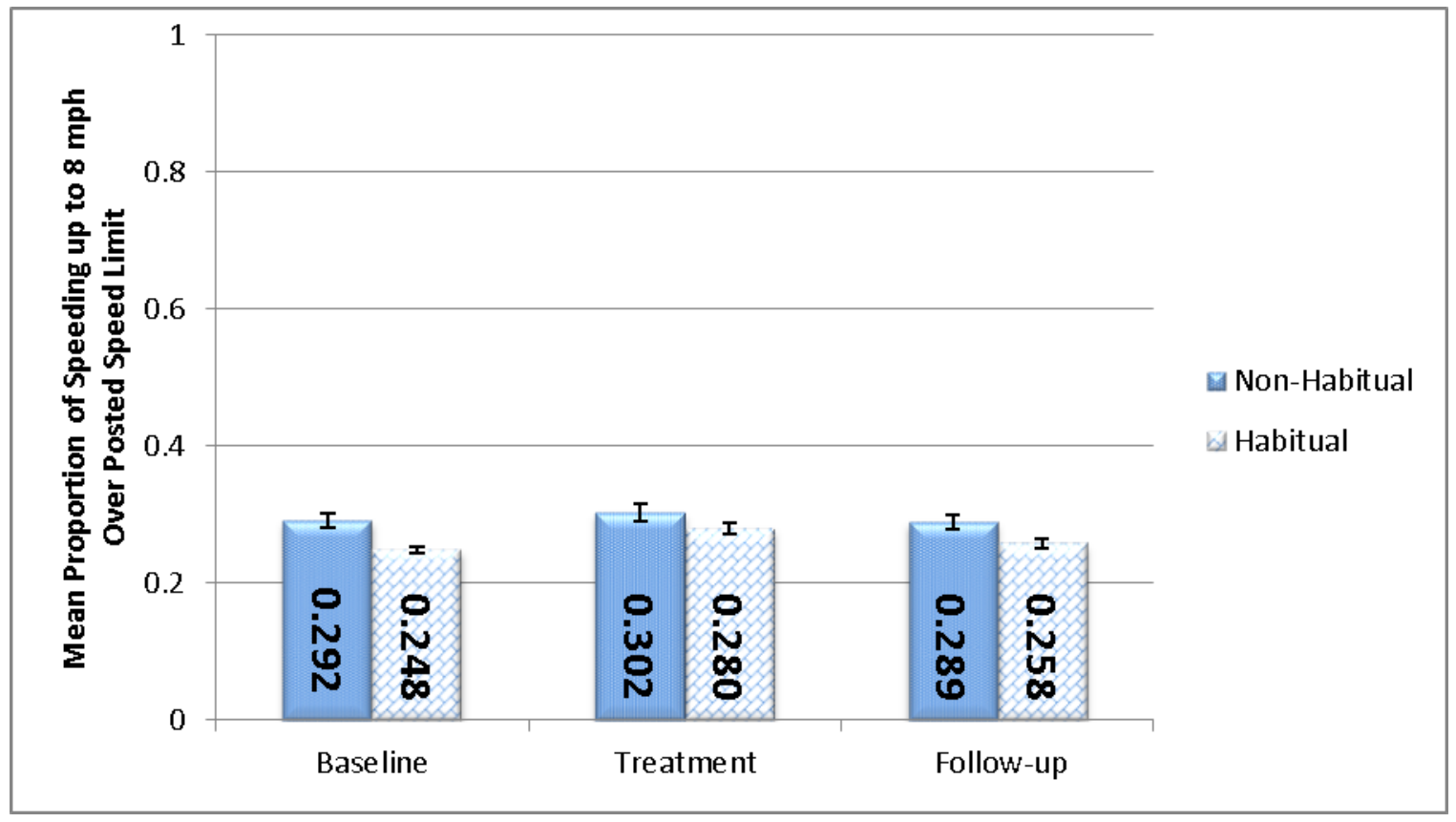

Figure 15. Mean proportion of each trip driving up to $8 \mathrm{mph}$ over the posted speed limit for habitual speeders and nonhabitual speeders in short condition by phase 


\subsubsection{Habitual Versus Nonhabitual Speeders Driving Over $8 \mathrm{mph}$ Above the Posted Speed Limit}

When analyzing the percent of speeding over $8 \mathrm{mph}$ over the speed limit, we found there was a robust main effect of the treatment phase, $F=37.90, p<.0001$ (see Figure 16). This effect was driven by a lower proportion of speeding over $8 \mathrm{mph}$ for each trip occurring during the treatment phase $(X=.14)$ relative to the baseline or follow-up phases $(X=.18$ and $X=.16$, respectively). Treatment was significantly below both baseline, $\mathrm{t}=7.94, \mathrm{p}<.0001$ and follow-up, $\mathrm{t}=-5.86, \mathrm{p}<$ .0001. Interestingly, follow-up was also below baseline, $\mathrm{t}=3.19, \mathrm{p}<.01$, indicating that speeding behavior stayed less frequent after treatment subsided. The bar graph below (Figure 16) shows that speeding behavior decreased dramatically during the treatment phase, suggesting that the alerts do have an influence on suppressing speeding behavior over $8 \mathrm{mph}$ above the posted speed limit.

Habitual speeding as a category was highly significant, $\mathrm{F}=80.04, \mathrm{p}<.0001$. Not surprisingly, habitual speeders had a much higher proportion of speeding over $8 \mathrm{mph}$ than nonhabitual speeders (See Figure 17).

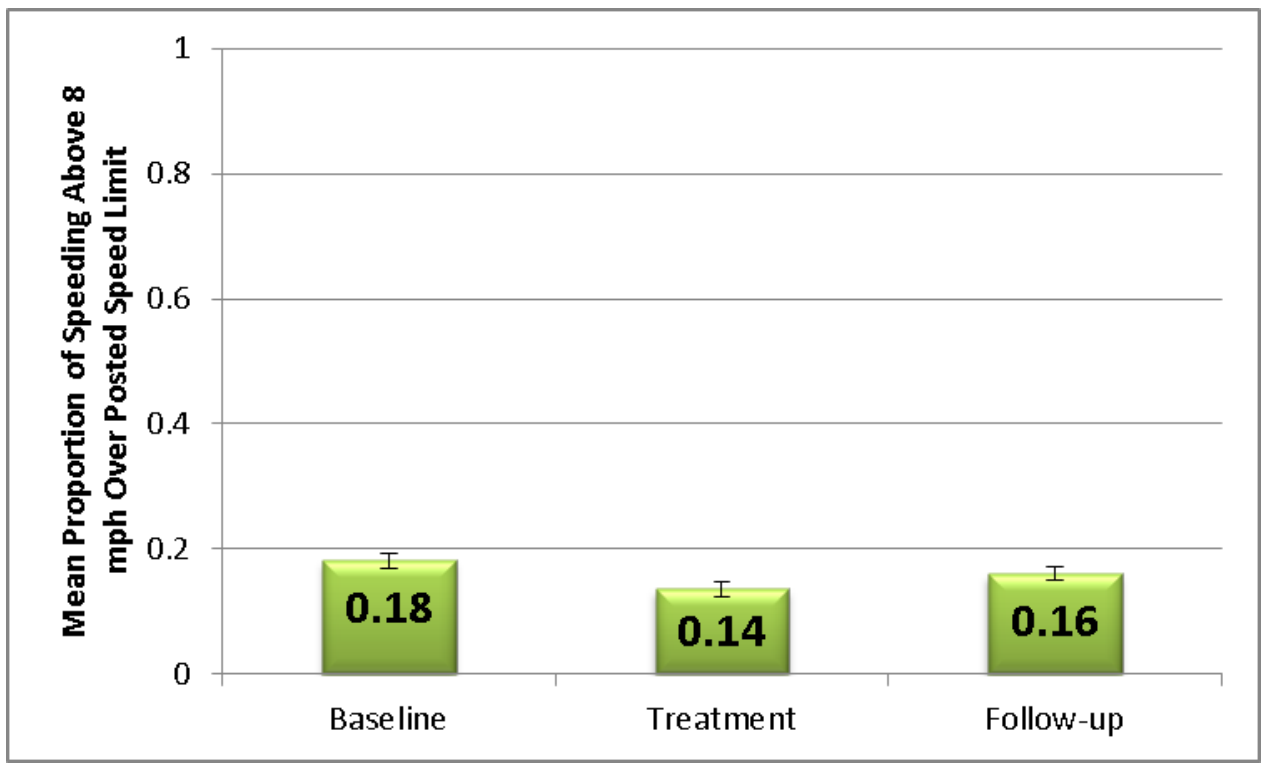

Figure 16. Mean proportion of each trip driving over $8 \mathrm{mph}$ above the posted speed limit for habitual speeders in short condition 


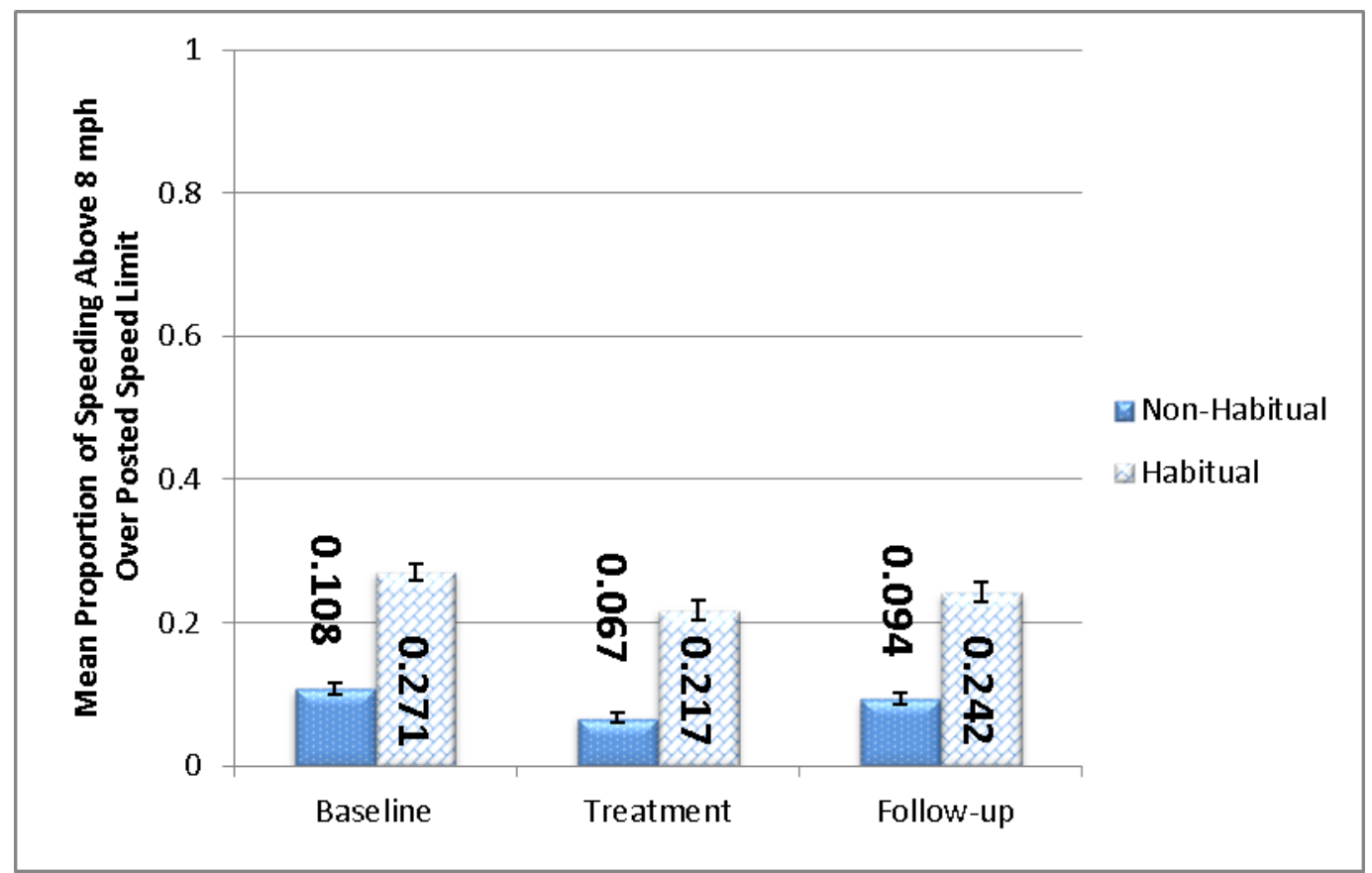

Figure 17. Mean proportion of each trip driving over $8 \mathrm{mph}$ above the posted speed limit for habitual speeders and nonhabitual speeders in short condition by phase

\subsubsection{Habitual Versus Nonhabitual Speeders Driving at Least $20 \mathrm{mph}$ Over the Posted Speed Limit}

When analyzing the proportion of speeding at least $20 \mathrm{mph}$ over the posted speed limit for habitual speeders, we found there was a strong effect of the treatment phase, $F=8.39, p<.001$. The proportion of speeding at least $20 \mathrm{mph}$ over the posted speed limit was less during the treatment phase relative to the baseline or follow-up phase (see Figure 18). Proportion of speeding at least 20 mph over the posted speed limit was significantly lower during the treatment phase $(\mathrm{X}=.018)$ than during the baseline phase $(\mathrm{X}=.026), \mathrm{t}=3.90, \mathrm{p}<.001$ or the follow-up phase, $\mathrm{t}=-2.30, \mathrm{p}<.05$ $(\mathrm{X}=.023)$. There was no significant difference between the baseline and follow-up phases $(\mathrm{X}=.023)$, $\mathrm{t}=1.39, \mathrm{p}>.05$. It seems that the alerts do have an effect on suppressing the speeding behavior, although the participants' behavior began to increase after the treatment was removed, it had not quite returned to its original level during the follow-up phase.

Habitual speeding as a category was highly significant, $F=127.76, \mathrm{p}<.0001$. Not surprisingly, habitual speeders had a much higher proportion of reckless speeding than nonhabitual speeders. In fact, the proportion of reckless speeding by nonhabitual speeders was almost nonexistent, indicating a strong reluctance to behave this way by this group (See Figure 19). 


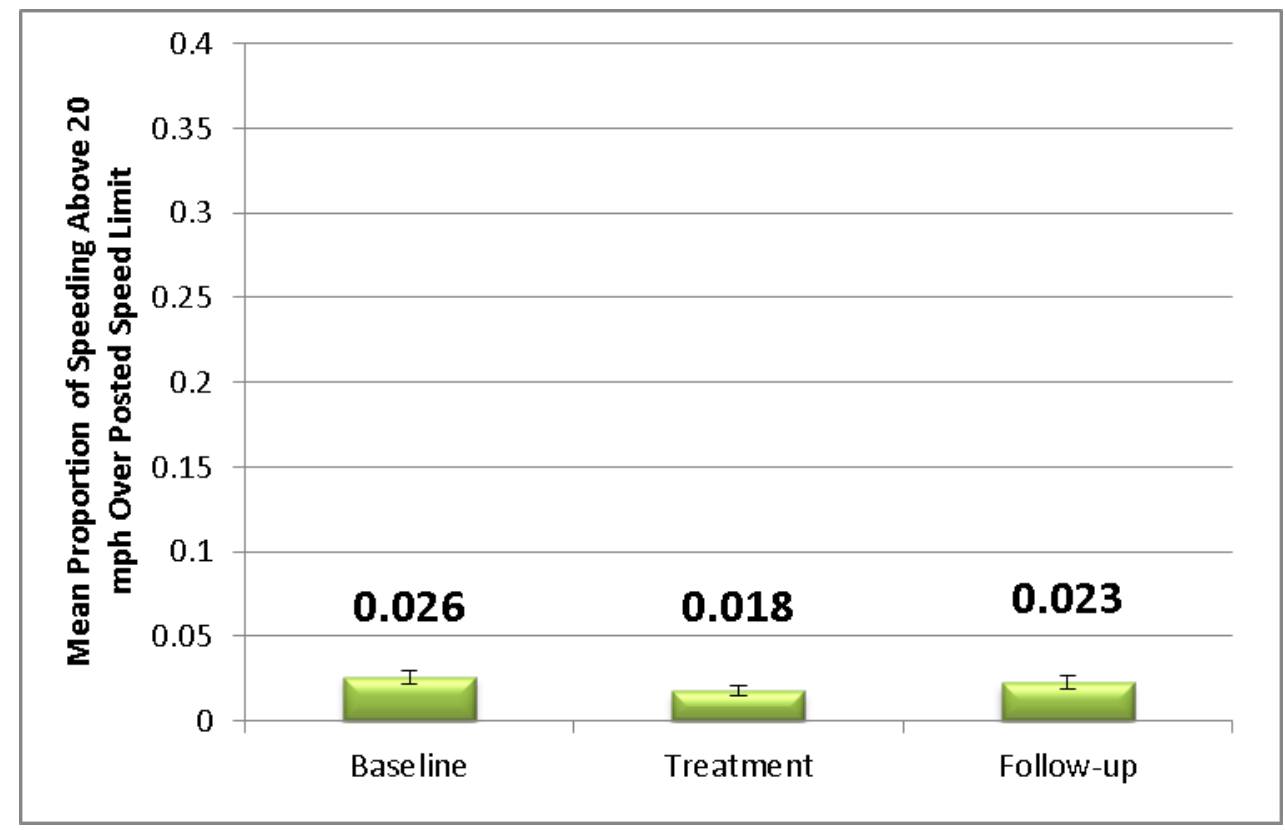

Figure 18. Mean proportion of driving at least $20 \mathrm{mph}$ over the posted speed limit for habitual speeders in short condition

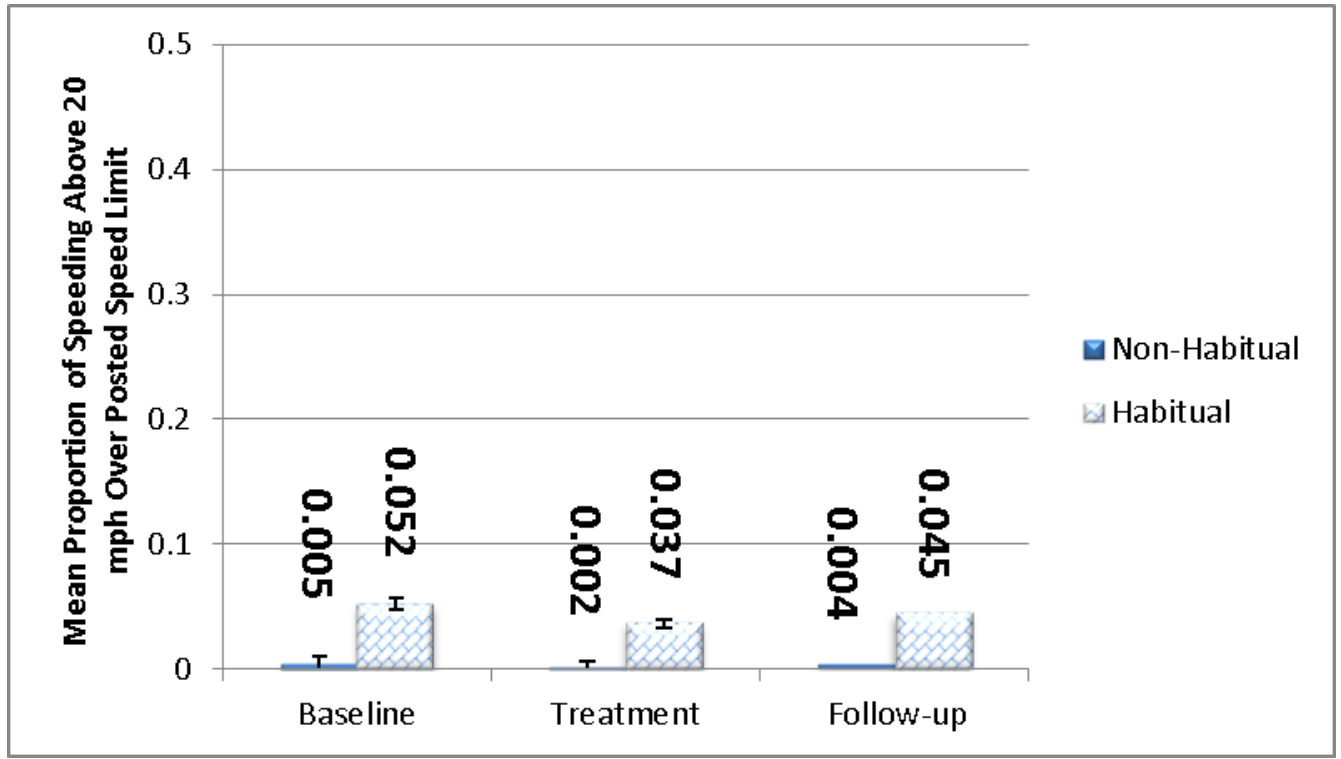

Figure 19. Mean proportion of each trip driving at least $20 \mathrm{mph}$ over the posted speed limit for habitual speeders and nonhabitual speeders in short condition by phase

\subsection{Ticketed Participants}

The emphasis of the following section is on a small subset of drivers ( 9 participants) who were ticketed for speeding at some point during the study and were part of the short duration condition. 
Of these 9 ticketed participants, 4 were also classified as habitual speeders. Given such a small sample, this may have created some anomalies in the data that cannot be fully explained without a larger sample size. Therefore, while this sub-group of participants may provide valuable insight into possible trends, it does not provide sufficient statistical power to reach strong conclusions about ticketing on behavior.

\subsubsection{Ticketed Participants Driving Over the Speed Limit}

Overall, there does seem to be a slight change in the proportion of speeding occurring during the treatment phase $(X=.43)$ relative to the baseline or follow-up phase $(X=.47$ and $X=.44$, respectively (see Figure 20). During the treatment phase, the proportion of driving over the posted speed limit appears to decline, relative to the baseline and follow-up phases (see Figure 20). Interestingly, once the alerts are removed, the behavior seems to continue in a manner similar to behavior during the treatment phase. The strength and significance of this relationship cannot be addressed with confidence, given the overall sample size of this group.

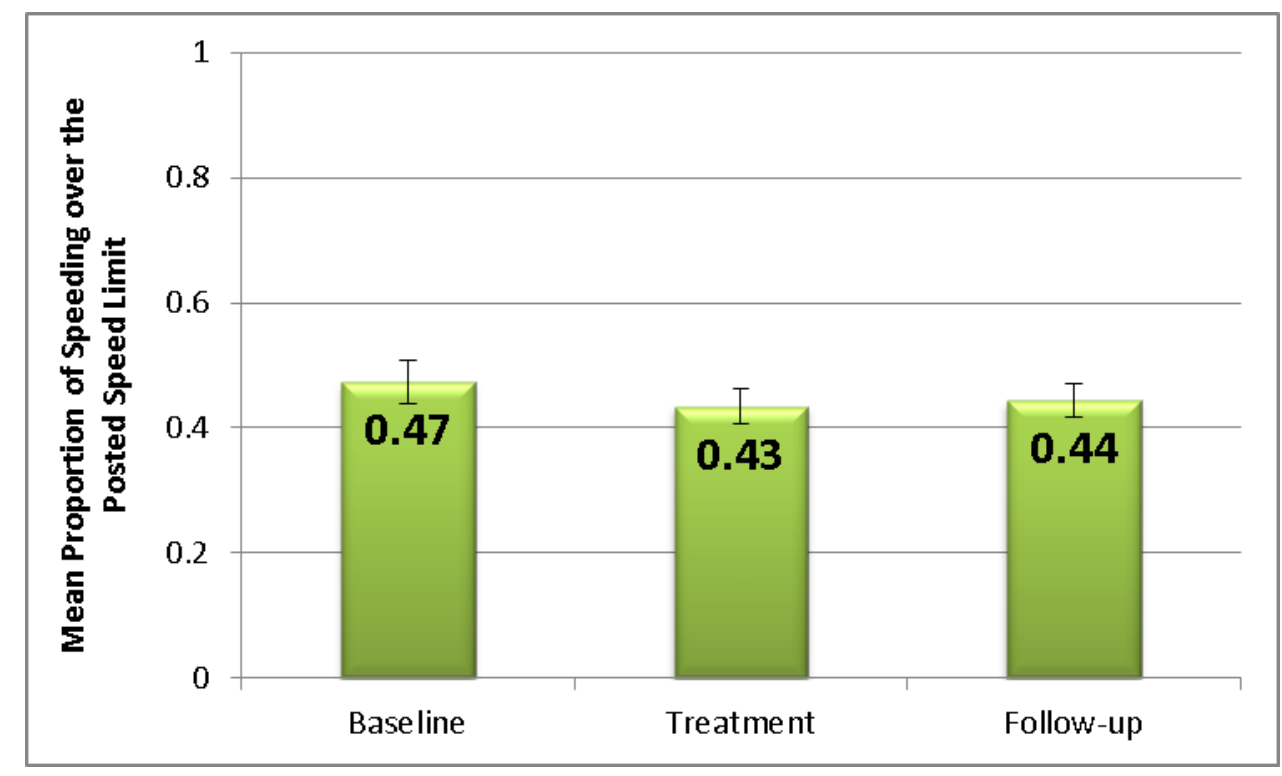

Figure 20. Mean proportion of ticketed drivers driving over the speed limit

\subsubsection{Ticketed Participants Speeding up to $8 \mathrm{mph}$ Above the Posted Speed Limit}

While the significance of the relationship cannot be addressed in this report for this group, the pattern of speeding up to $8 \mathrm{mph}$ over the posted speed limit for the ticketed participants appears to be similar to participants overall in the short duration for speeds up to $8 \mathrm{mph}$ above the posted speed limit. During the treatment phase, the alert appears to modify the participant's speeding behavior (See Figure 21). Their average proportion of speeding up to $8 \mathrm{mph}$ above the posted speed limit increases during the treatment phase $(X=.28)$ relative to the baseline $(X=.26)$ and follow-up phases $(\mathrm{X}=.27)$. As with the overall short duration participants, this may be a reflection of their responding to the alerts by adjusting their speed to something below the threshold. 


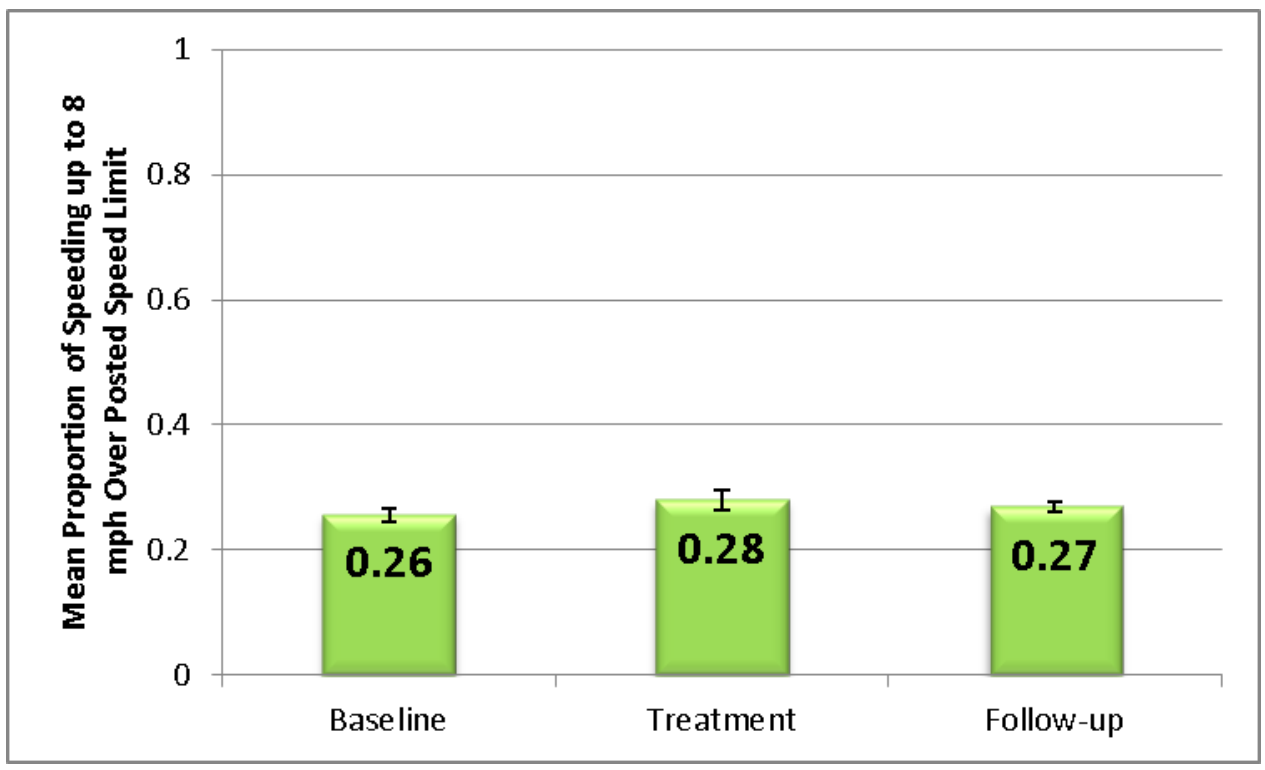

Figure 21. Mean proportion of ticketed drivers driving up to $8 \mathrm{mph}$ above the posted speed limit in short duration condition

\subsubsection{Ticketed Participants Speeding Over $8 \mathrm{mph}$ Above the Posted Speed Limit}

This section examines the percent of each trip that a participant was speeding over $8 \mathrm{mph}$ above the speed limit for ticketed participants. As stated earlier, if the alert received during the treatment phase is effective at modifying the participants behavior, their average proportion of speeding over $8 \mathrm{mph}$ above the posted speed limit per trip should decline. However, the strength and significance of this relationship cannot be addressed with confidence given the overall sample size of this group.

The bar graph below shows that the speeding behavior decreased dramatically during the treatment phase $(X=.16$; see Figure 22), suggesting that the alerts do have a suppressing influence on speeding behavior over the threshold of $8 \mathrm{mph}$. Interestingly, it appears that this difference was sustained during the 2 week follow-up phase for these participants. Their speeds increased slightly, but were not back to baseline levels $(\mathrm{X}=.22)$ during the 2 week follow-up $(\mathrm{X}=.18)$. 


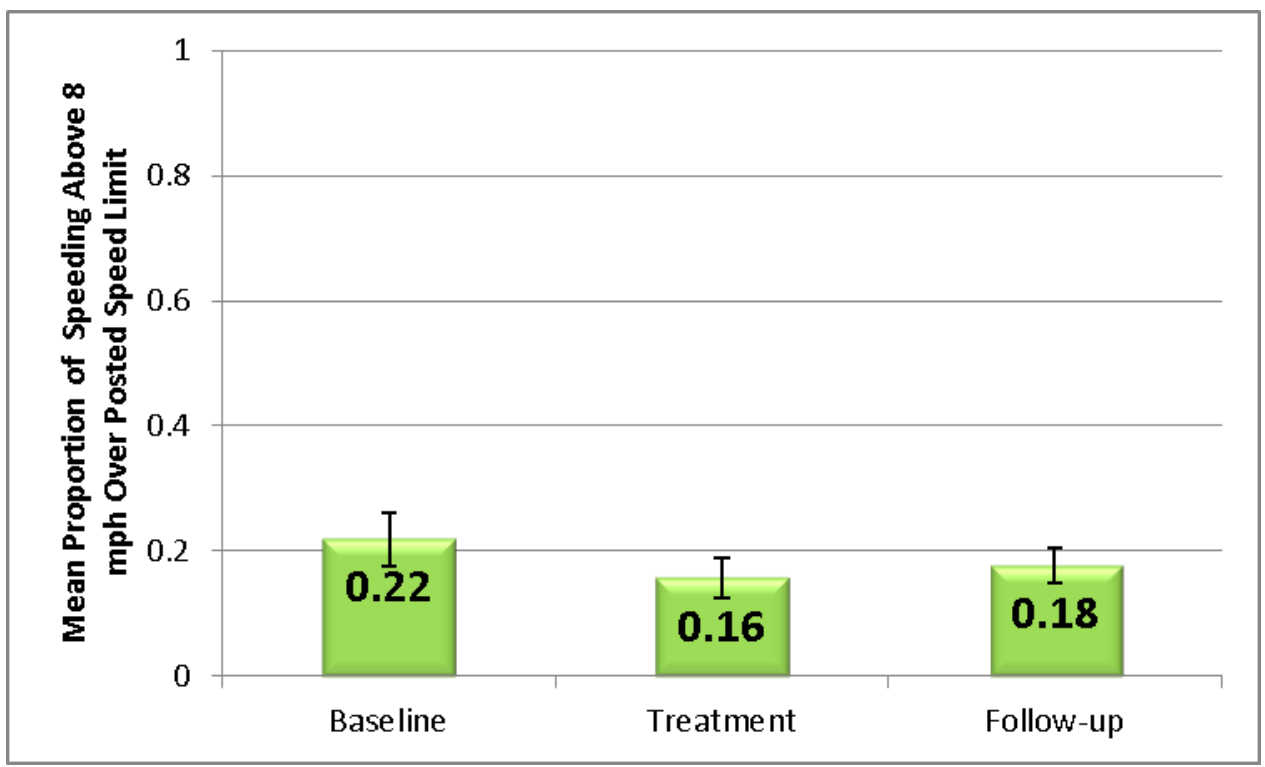

Figure 22. Mean proportion of ticketed drivers driving over $8 \mathrm{mph}$ above the posted speed limit in short duration condition

\subsubsection{Ticketed Participants Speeding at Least 20 mph Over the Posted Speed Limit}

As shown in the bar chart below (Figure 23), the trend identified for the ticketed participants seems to be similar to the data from the overall participants. For the ticketed participants, speeding at least $20 \mathrm{mph}$ over the posted speed limit appears to decrease slightly during the treatment phase $(\mathrm{X}=.026)$ and then is maintained at this level once the alerts are silenced during the follow-up $(\mathrm{X}=.33)$, which is well below the original baseline level $(\mathrm{X}=.045)$. Once again, it is important to note the small sample size. 


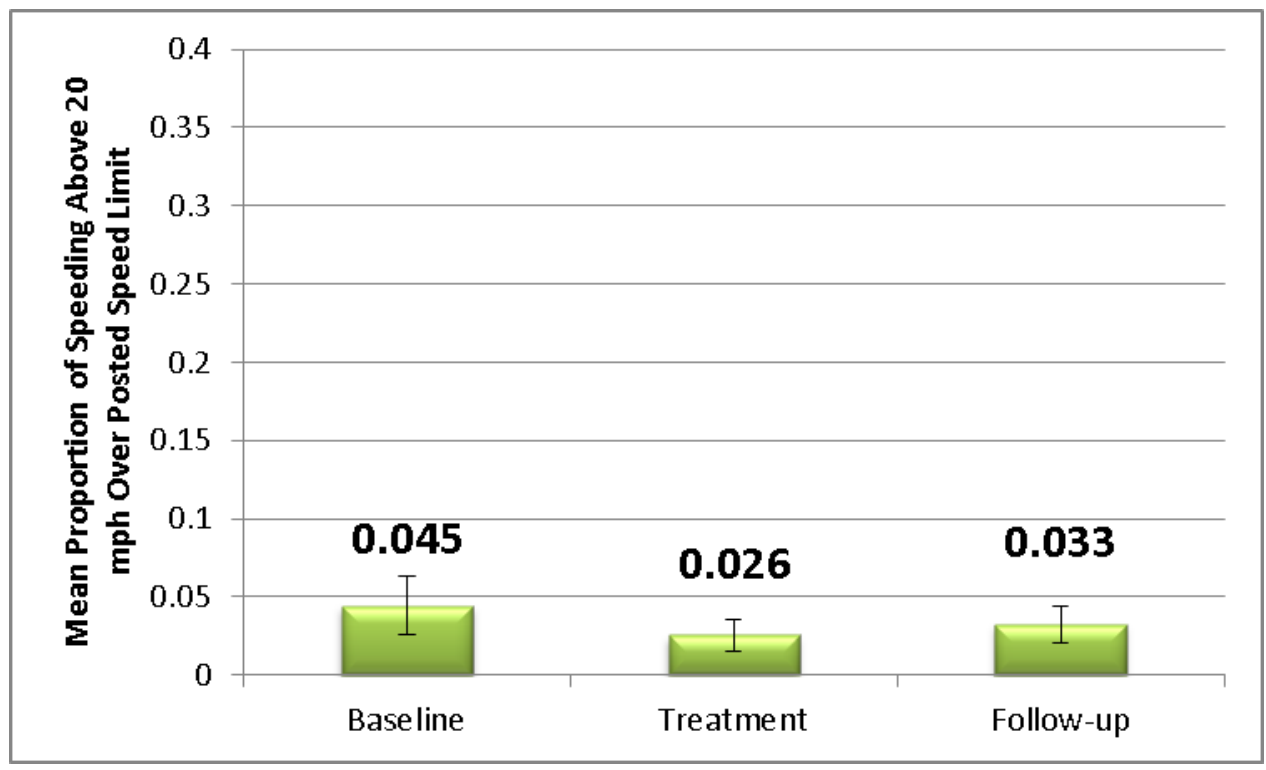

Figure 23. Mean proportion of ticketed drivers driving at least $20 \mathrm{mph}$ over the posted speed limit in long-duration condition

The previous discussions focused on drivers in the shorter treatment condition. Overall, the alerts provided by the speed monitoring/warning system had a positive effect on the participants' speeding behavior. There was a noticeable decline in speeding over $8 \mathrm{mph}$ above the posted speed limit and at least $20 \mathrm{mph}$ over the posted speed limit during the treatment phase. In addition, there was an increase in driving speeds above the posted speed limit, but below the alert threshold (up to $8 \mathrm{mph}$ above the posted speed limit). There is some evidence suggesting that the alerts effect is maintained for some time after the treatment phase has ended.

\subsection{Long-Duration Participants}

It is possible that longer exposure to the treatment would produce a stronger or different pattern of effects on the speeding behavior. Consequently, the emphasis of the following section is on a small subset of drivers (5 participants) who participated in the longer treatment condition, defined as those participants who experienced a baseline period of 2 weeks, the treatment phase for 8 weeks and then the follow-up phase for four weeks. It is important to note that 2 of the participants in the long-duration condition met the study criteria for habitual speeders. Given such a small sample, this may have created some anomalies in the data that cannot be fully explained without a larger sample size. Therefore, while this sub-group of participants may provide valuable insight into possible trends and for experimental design in subsequent, longer-term evaluation studies, it does not provide sufficient statistical power to reach strong conclusions about temporal effects of the treatment.

\subsubsection{Long-Duration Participants Driving Over the Speed Limit}

Overall, there does seem to be a slight change in the proportion of speeding occurring during the treatment phase $(\mathrm{X}=.47)$ relative to the baseline or follow-up phase $(\mathrm{X}=.50$ and $\mathrm{M}=.51$, 
respectively (see Figure 24). During the treatment phase, the proportion of driving over the posted speed limit appears to decline relative to the baseline and follow-up phase participants (see Figure 17). However, once the alerts are removed, the behavior seems to return to the original proportion. The strength and significance of this relationship cannot be addressed with confidence given the overall sample size of this group.

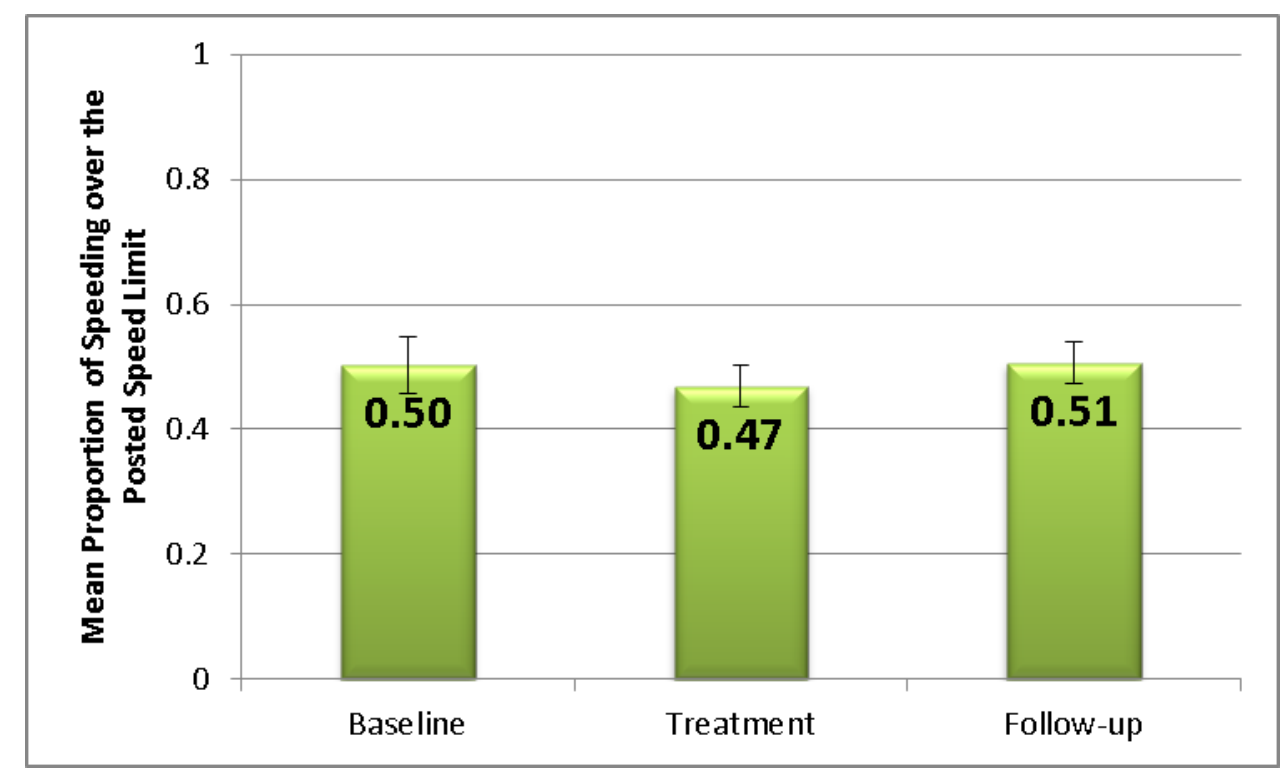

Figure 24. Mean proportion of driving over the speed limit in long-duration condition

\subsubsection{Long-Duration Participants Speeding Up to $8 \mathrm{mph}$ Over the Posted Speed Limit}

While the significance of the relationship cannot be addressed in this report for this group, the pattern of speeding up to $8 \mathrm{mph}$ over the posted speed limit for the long-duration participants appears to be similar to participants in the short duration for speeds up to $8 \mathrm{mph}$ above the posted speed limit. During the treatment phase, the alert appears to modify the participant's speeding behavior (See Figure 25). Their average proportion of speeding up to $8 \mathrm{mph}$ above the posted speed limit increases during the treatment phase $(X=.28)$ relative to the baseline $(X=.27)$ and follow-up phases $(\mathrm{X}=.27)$. As with the short-duration participants, this may be a reflection of their responding to the alerts by adjusting their speed to something below the threshold. For the long-duration participants, the speeding up to $8 \mathrm{mph}$ is the same for both the baseline and the follow-up phases. 


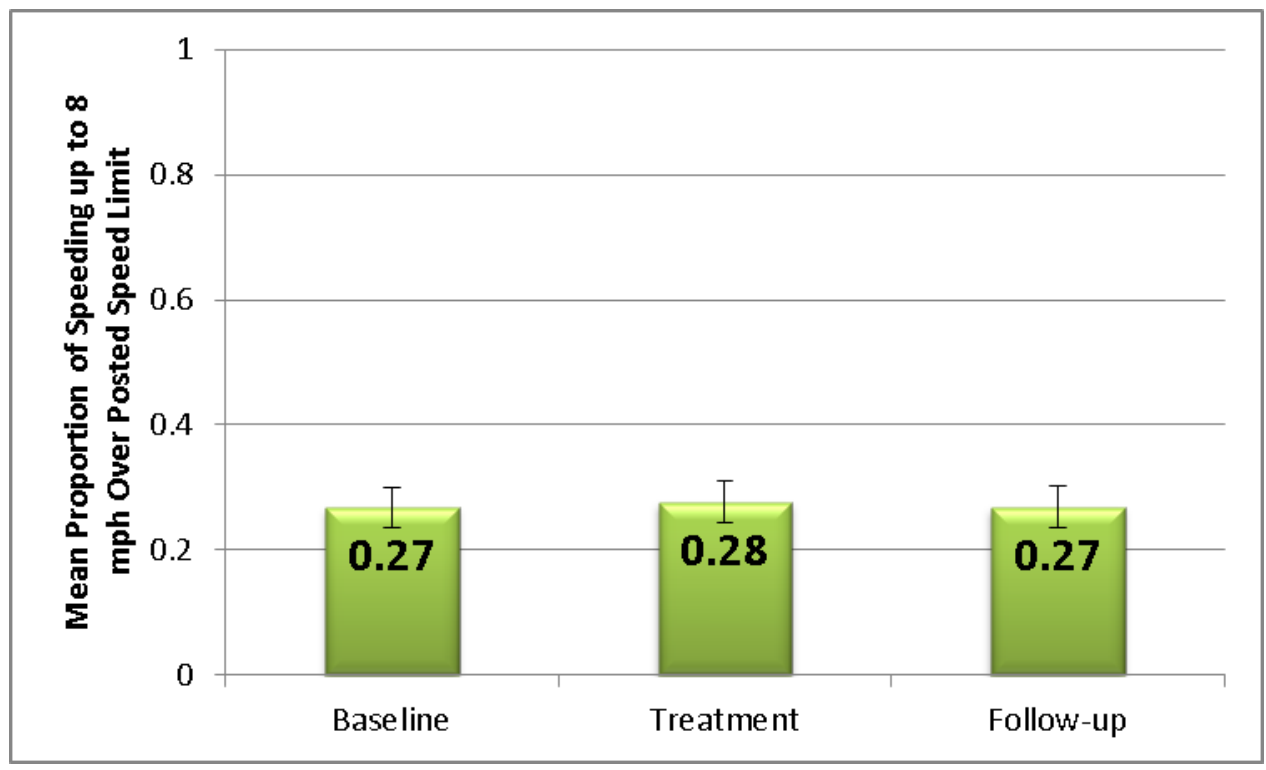

Figure 25. Mean proportion of driving up to $8 \mathrm{mph}$ above the posted speed limit in long duration condition

\subsubsection{Long-Duration Participants Speeding Over $8 \mathrm{mph}$ Over the Posted Speed Limit}

This section examines the percent of each trip that a participant was speeding over $8 \mathrm{mph}$ above the speed limit for participants in the long-duration condition. As stated earlier, if the alert received during the treatment phase is effective at modifying the participants behavior, their average proportion of speeding over $8 \mathrm{mph}$ above the posted speed limit per trip should decline. However, the strength and significance of this relationship cannot be addressed with confidence given the overall sample size of this group.

The bar graph below shows that the speeding behavior decreased dramatically during the treatment phase $(X=.19$; see Figure 26), suggesting that the alerts do have a suppressing influence on speeding behavior over the threshold of $8 \mathrm{mph}$. However, it appears that this effect was not sustained during the 4 week follow-up phase for these participants. Their speeds increased back to baseline levels $(\mathrm{X}=.23)$ during the 4 week follow-up $(\mathrm{X}=.24)$. 


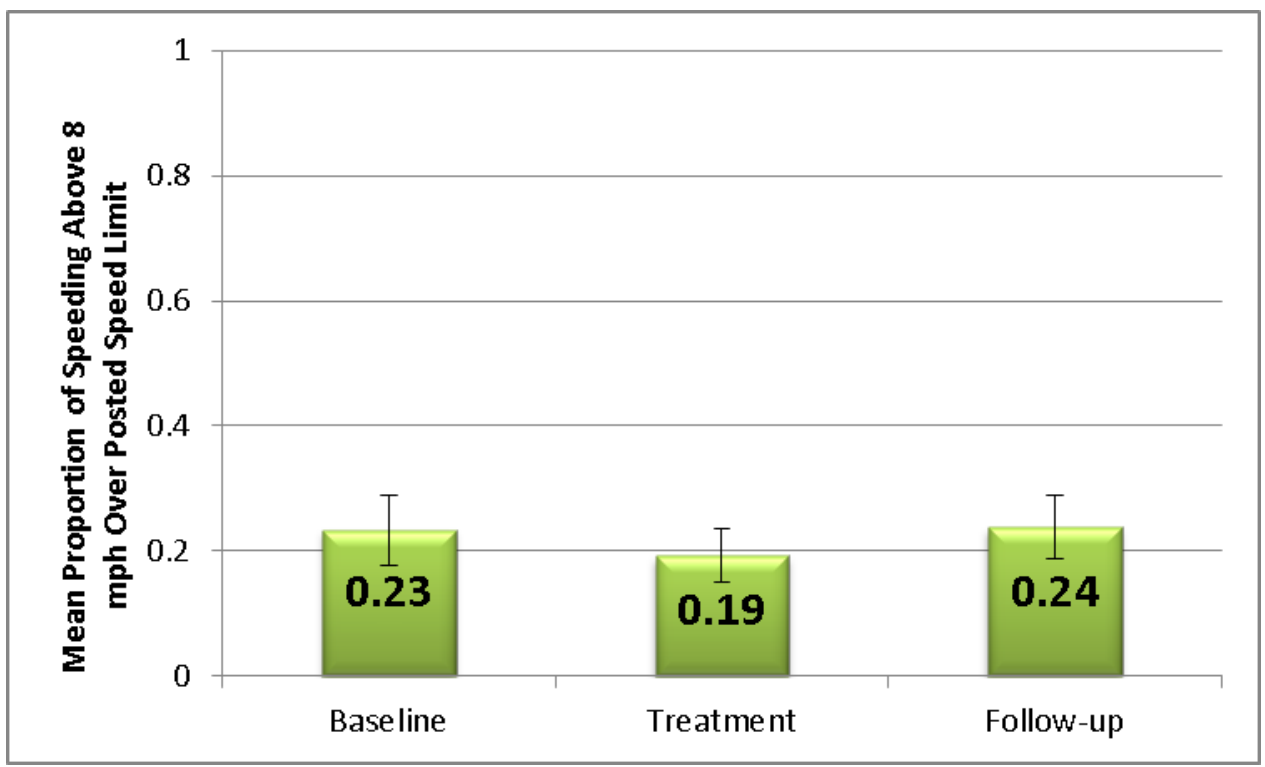

Figure 26. Mean proportion of driving over $8 \mathrm{mph}$ above the posted speed limit in long-duration condition

\subsubsection{Long-Duration Participants Speeding at Least $20 \mathrm{mph}$ Over the Posted Speed Limit}

As shown in the bar chart below (Figure 27), the trend identified for the long-duration participants seems to be similar to the data from the short-duration participants for baseline and treatment. For the short-duration participants a lower proportion of speeding at least $20 \mathrm{mph}$ over the posted speed limit occurred during the treatment phase $(X=.022)$ vs. the baseline $(X=.026)$ or follow-up phase $(\mathrm{X}=.022)$. For the long-duration participants, speeding at least $20 \mathrm{mph}$ over the posted speed limit appears to decrease slightly during the treatment phase $(\mathrm{X}=.03)$ and then increase once the alerts are silenced during the follow-up $(\mathrm{X}=.05)$. Once again, it is important to note that due to the small sample size and the fact that two participants within this condition were classified as habitual speeders - participants who drove more than 30 percent of their total miles traveled speeding $8 \mathrm{mph}$ over the posted speed limit during the baseline phase. Both of these factors may have contributed to the anomalous findings for this speeding category, and the data is too noisy to draw strong conclusion with any confidence. 


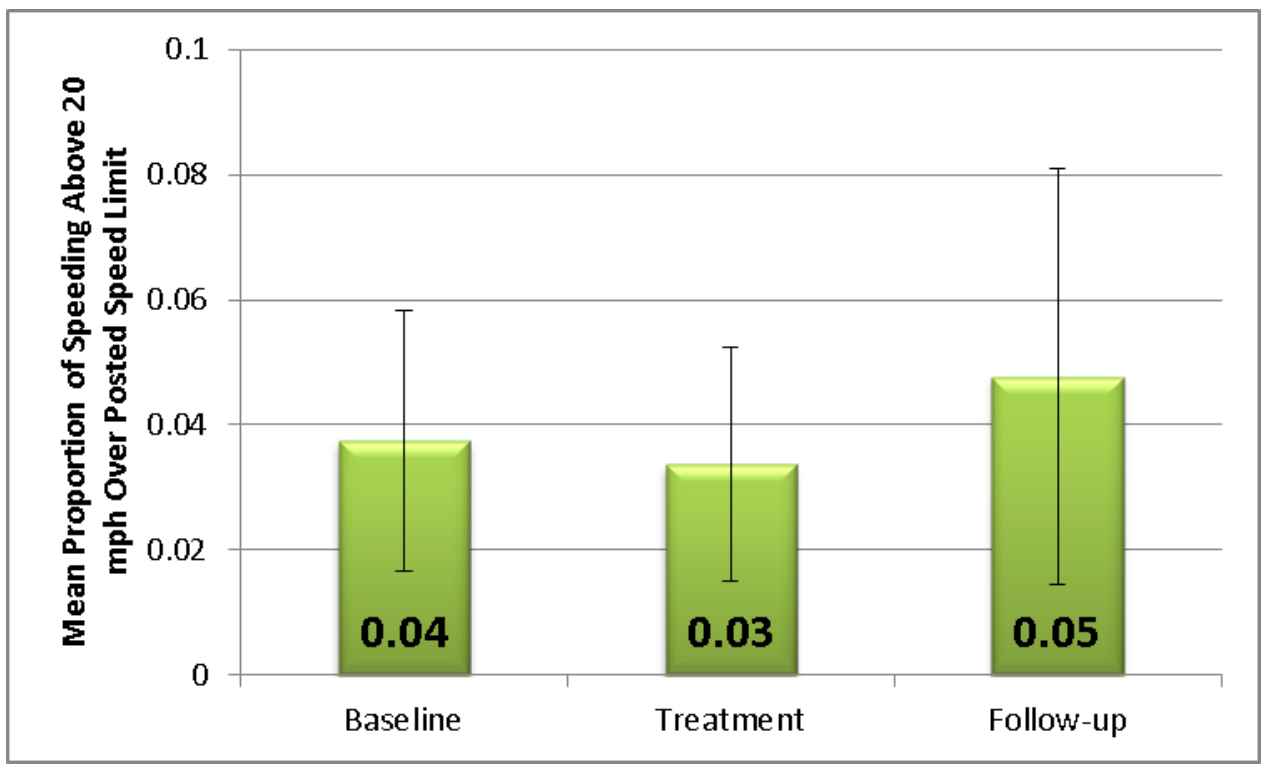

Figure 27. Mean proportion of driving at least $20 \mathrm{mph}$ over the posted speed limit in long-duration condition

\subsection{Short-Duration Participants Speeding behavior Related to Road Type}

Due to differences in roadway geometry and driver motivations to use the various road types, speeding behavior may vary based on road type. The following analysis divided roadways into four categories: (a) limited access), (b) major arterial, (c) minor arterials, and (d) local, and examined short-duration participants' speeding behavior during each of the three study phases on each of the four road types. In general, the proportion of speeding estimates for all four road classes followed the expected patterns. Proportion of speeding on limited access roads was higher than on major arterials, which in turn was higher than on minor arterials and local roads.

\subsubsection{Driving Over the Speed Limit by Road Type}

When analyzing driving over the speed limit by road type for the short-duration condition, there was a robust effect of the treatment phase, $F=17.88, \mathrm{p}<.0001$. That is, speeding on all road types declined during the treatment phase (see Figure 28). Road type had a robust, significant main effect, $\mathrm{F}=46.48, \mathrm{p}<.0001$, indicating that the mean percent of each trip that a driver was speeding was highest on limited access roads $(X=.67)$ and lowest on local roads $(X=.47)$. The interaction of road type and treatment phase was not significant, $\mathrm{F}<1$. Regardless of road type, participants' speeding behavior was reduced by the presence of the alert (treatment phase), but then increased again when the speeding alert was removed. 


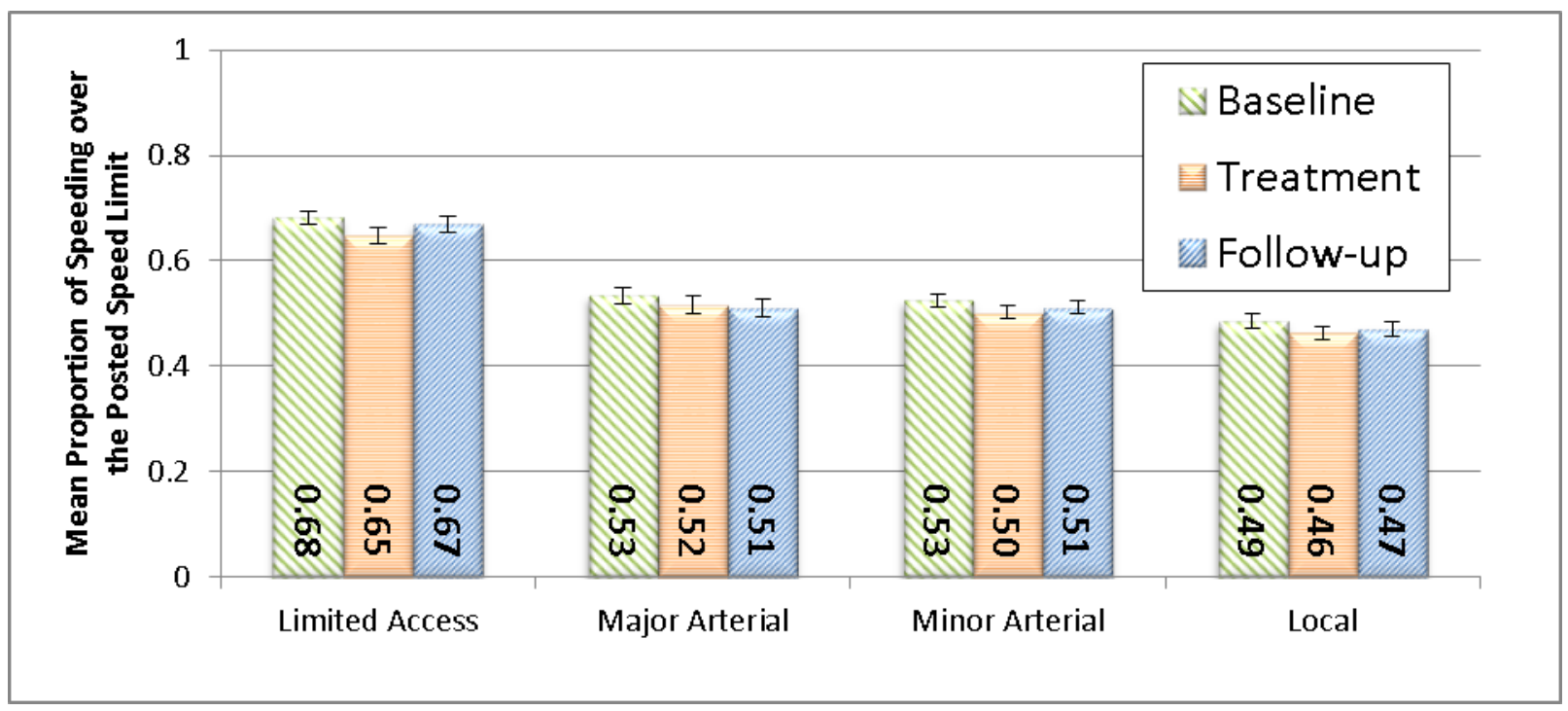

Figure 28. Mean proportion of driving over the posted speed limited by road type in shortduration condition

\subsubsection{Speeding Up to $8 \mathrm{mph}$ by Road Type}

When analyzing speeding up to $8 \mathrm{mph}$ by road type for the short-duration condition, there was a robust effect of the treatment phase, $F=59.73, \mathrm{p}<.0001$. The trends were similar to those presented earlier for this speeding category. The proportion of speeding up to $8 \mathrm{mph}$ above the posted speed limit increased on all road types during the treatment phase, suggesting that there was a downward shift in speeding behavior from driving at higher speeds to electing to drive at a speed that is below the threshold for alerts ( $8 \mathrm{mph}$ above the posted speed limit) during the treatment phase (see Figure 29). There was a significant main effect of road type, $F=10.07, p<.0001$. Again the trend was the same as above, with a somewhat linear decline in average percent of speeding from limited access roads to local roads, although flatter with sideways movement from minor arterials to local roads. There was no significant interaction of road type and treatment phase, $\mathrm{F}=$ $1.86, \mathrm{p}>.05$. 


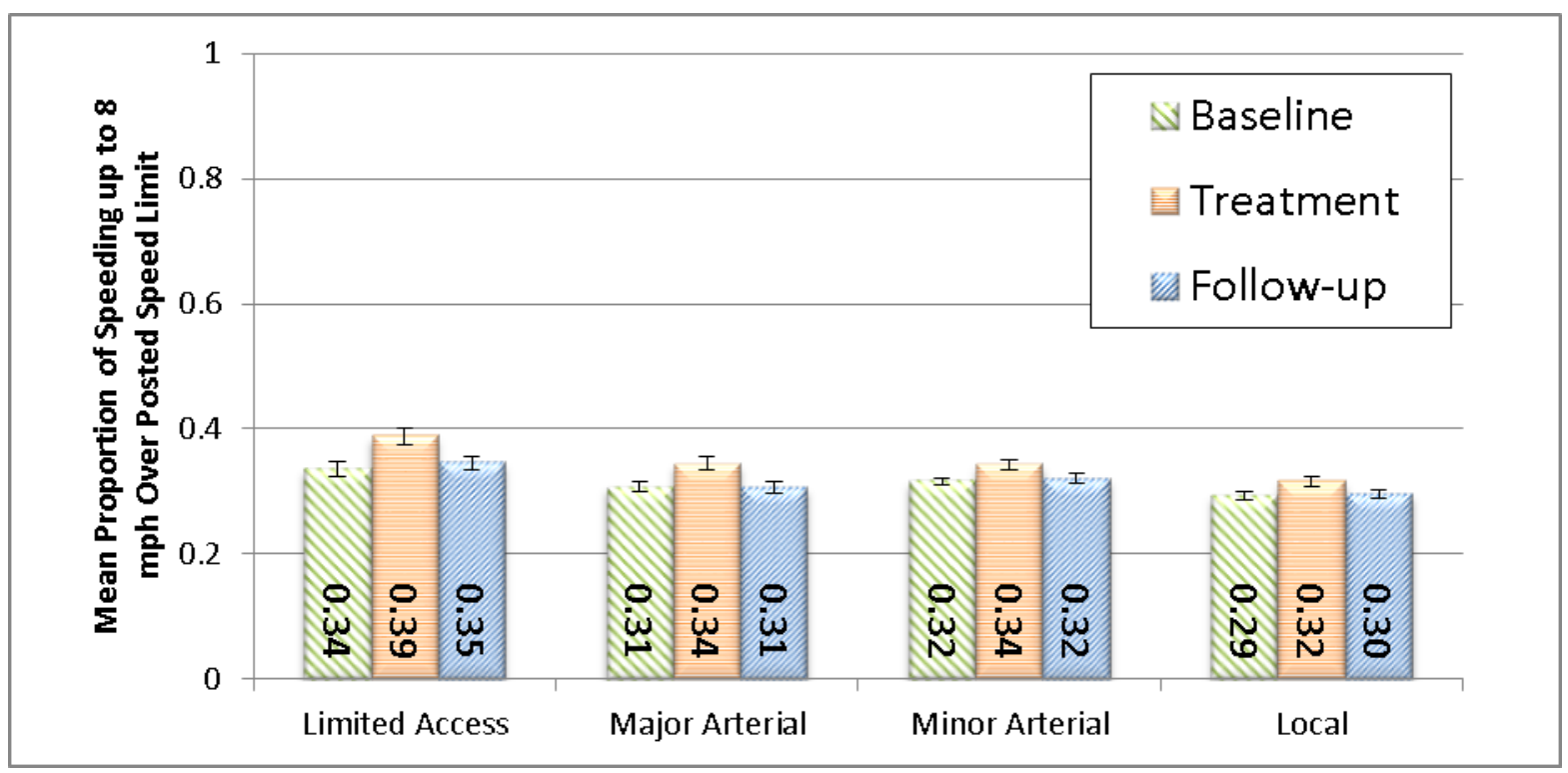

Figure 29. Mean proportion of driving up to $8 \mathrm{mph}$ above the posted speed limit by road type in short-duration condition

\subsubsection{Speeding Over $8 \mathrm{mph}$ by Road Type}

When analyzing speeding over $8 \mathrm{mph}$ by road type for the short-duration condition, there was a robust effect of the treatment phase, $\mathrm{F}=102.17, \mathrm{p}<.0001$, suggesting that speeding over $8 \mathrm{mph}$ above the posted speed limit decreased dramatically during the treatment phase on all road types, and that the alerts do have an influence on suppressing speeding behavior for speeds over $8 \mathrm{mph}$ above the posted speed limit (see Figure 30). There was a significant main effect of road type, F = $13.03, \mathrm{p}<.0001$. The trend was the same as above, with a somewhat linear decline in the proportion of speeding from limited access roads to local roads. There was not a significant interaction of road type and treatment phase, $\mathrm{F}<1$.

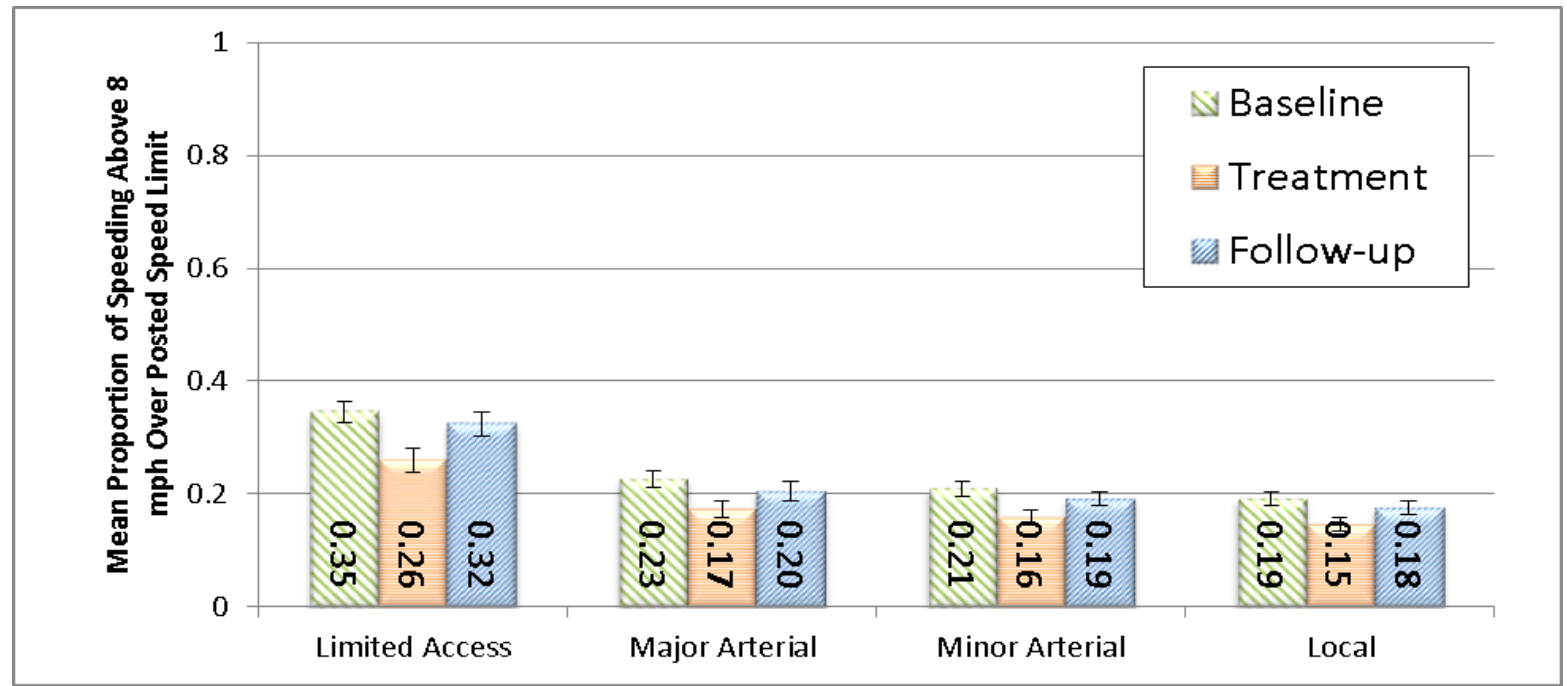

Figure 30. Mean proportion of driving over $8 \mathrm{mph}$ above the posted speed limit by road type in short-duration condition 


\subsubsection{Speeding at Least $20 \mathrm{mph}$ Over the Posted Speed Limit by Road Type}

When analyzing speeding at least $20 \mathrm{mph}$ over the posted speed limit by road type for the shortduration condition, there was a robust effect of the treatment phase, $\mathrm{F}=39.28, \mathrm{p}<.0001$. Driving over at least $20 \mathrm{mph}$ over the posted speed limit declined during the treatment phase for all road types (see Figure 31). There was a significant main effect of road type, $F=3.63, p<.05$. There was a linear decline in speeding from limited access roads to local roads; with a steeper drop off from limited access to the other road types. This may reflect a greater opportunity to reach speeds in excess of $20 \mathrm{mph}$ over the posted speed limit on limited access roads as compared to the other road types. There was not a significant interaction of road type and treatment phase, $\mathrm{F}<1$.

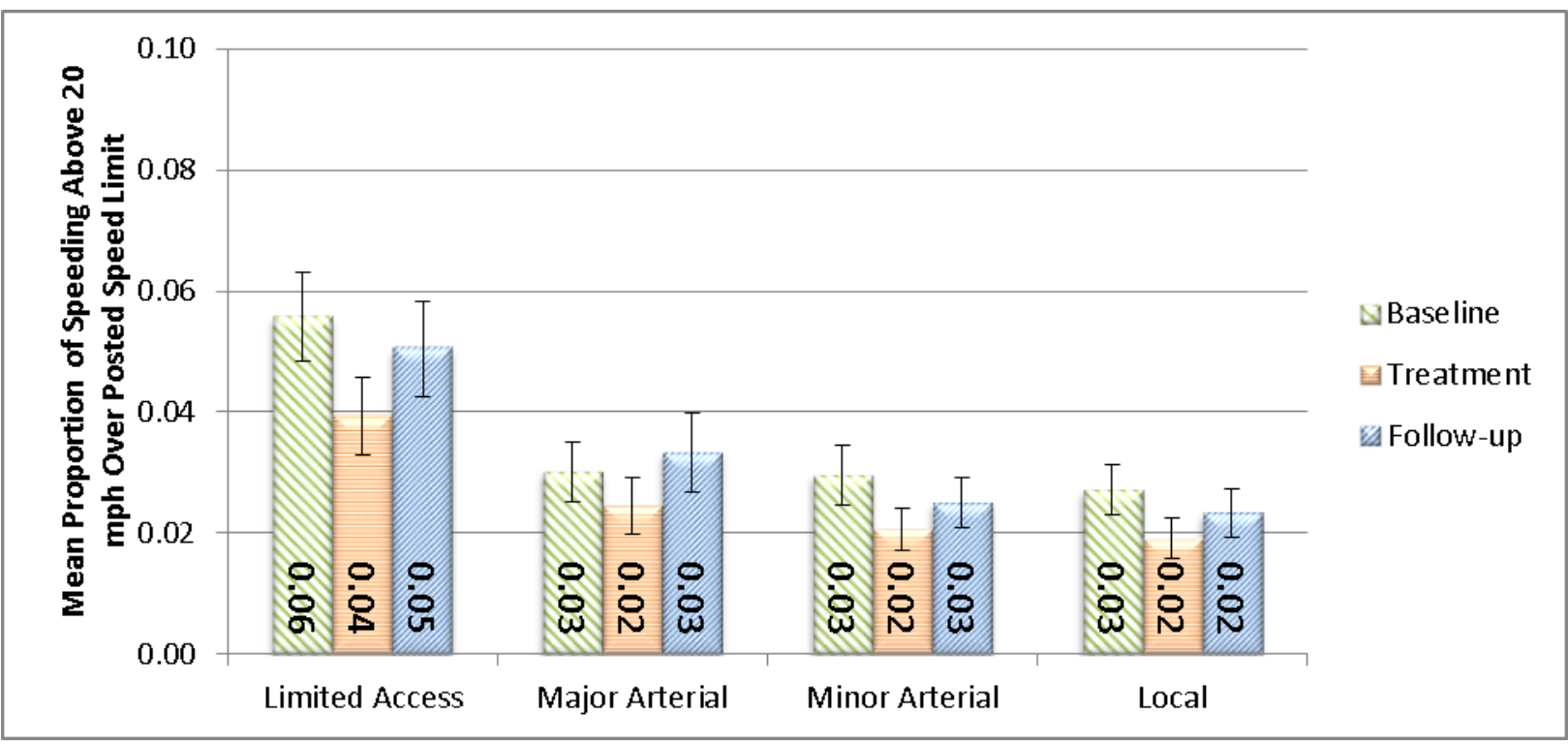

Figure 31. Mean proportion of driving $20 \mathrm{mph}$ over the posted speed limit in short-duration condition

\subsection{Summary of Results}

The current study's findings suggest that the verbal alerts provided by the system were successful in producing short-term changes in driving behavior. The true measure of effectiveness of the system, in this study, is the change in average proportion of speeding over $8 \mathrm{mph}$ above the posted speed limit, which is the speed at which the threshold for the alert was set in the current study. Overall, the average proportion of speeding above the threshold declined significantly during the course of the treatment phase for drivers in the short-duration condition, indicating that the presence of audio alerts does have a deterring effect on speeding behavior. In addition, once the treatment was lifted, there was evidence suggesting a sustained change in driving behavior for some participants. Although the proportion of speeding above the threshold during the two week follow-up period was higher than the proportion of speeding during the treatment phase, the follow-up speeds were significantly lower than those recorded during the baseline phase. 
The effects seemed to be similar for habitual speeders, where there was a decline in the proportion of speeding above the threshold during the treatment phase; however, the speeding behavior resumed once the alerts were removed. This group of drivers, on average, drove at speeds greater than $8 \mathrm{mph}$ over the speed limit for at least 30 percent of their baseline trips, and may be more willing to risk receiving a speeding violation. Thus, from a safety perspective, they may stand to benefit the most from using a speed monitoring/warning system.

It is also important to note that, while the significance of the effects for the long-duration condition could not be addressed with confidence due to the small sample size (five participants), the trends seem to echo those from the short-duration condition, providing preliminary evidence for the potential to use these systems as a tool for reducing speeding behavior.

\subsection{Feasibility of Implementing a Large-Scale Program}

From its inception, there were dual goals for this pilot assessment. The first was to identify whether these devices could decrease speeding. The second was to determine the feasibility of implementing a voluntary large scale study involving the use of speed monitoring/warning systems. Overall, the results described above suggest that providing drivers with feedback regarding their speed will prompt them to reduce their speeding behavior. However, there are a variety of aspects related to successfully implementing this type of voluntary program on a larger scale. These include factors related to the perceptions and motivations of the participants, and factors related to the success and practicality of the equipment, as well as the procedures required to implement, manage, and maintain the program. The sections below provide a brief description of the participants' overall impressions and experiences with the system, as well as factors that must be considered prior to implementing this type of program on a larger scale.

\subsection{User Acceptance}

One of the key measures of successfully implementing an in-vehicle speed monitoring/warning program is user acceptance. Voluntary use and impacts on driver behavior may be influenced in opposite ways by system features. There is an inherent trade-off between the effectiveness of the device in affecting driver behavior and the willingness of drivers to install and continue to use the device. This issue has been addressed in previous evaluation and design work related to enhanced seat belt reminders, crash warning systems, fuel economy displays, and teen driver monitoring programs (McCartt, Farmer, \& Jenness; 2010; NHTSA, 2006; Lerner, Singer, Huey, \& Jenness, 2007; Manser, Rakausskas, Graving, \& Jenness; 2010; Jenness, Singer, Walrath, \& Lubar, 2009) . Given that this pilot study is examining voluntary use of a speed warning system, the problems of user acceptance become greater obstacles.

Participants' overall experiences and acceptance of the speed monitoring/warning device and study methodology were ascertained from the debriefing session that was conducted with each participant at the completion of study involvement. The questionnaire focused on the following: perceived benefits to the participant; adequacy of the incentive; motivation to participate in a program; 
problems with the system; positive effects on behavior; negative effects on behavior; impacts on own and family use of the vehicle and family conflicts; influences on social aspects of driving (passengers, embarrassment); willingness to accept the device, likelihood of using the device after the conclusion of the study, and suggested improvements to hardware, communications, or procedures.

Overall, participants' experience with the system was positive. Among the 83 participants, 65 reported having positive or very positive experiences, 15 did not feel positive or negative about their experience, and only 3 felt that their experience was negative. Ninety-six percent of participants indicated that they would be willing to participate in another larger scale research study with a longer duration. Fifty-seven percent of the participants felt that they would continue to use the system even after the study was over. Ninety-six percent indicated that they would be willing to participate in another larger scale study with a longer duration.

When asked to openly comment on their overall experiences during the study and with the device, participants' opinions were mixed, but mostly positive. A summary of their comments include:

- Overall, the device was accurate when monitoring their speed in relation to the posted speed limit. However, some felt that the threshold for alerts should be higher.

- When the device was activated to provide alerts, it encouraged the driver to monitor their driving behavior.

- Passengers were interested in acquiring the device for their own vehicles.

- The device should be standard issue in all vehicles.

- The volume for the alerts needed to be raised. Participants often felt that the alerts were competing with the radio, noise from the environment when the sunroof was open and traffic on the highways.

- Some participants felt the speeding alert was annoying, especially when the participant was driving at the prevailing speed.

When asked about the overall accuracy and effectiveness of the device, findings were mixed. Eightyseven percent of the participants indicated that they were more likely to monitor their speedometer once the system alerts were activated. However, while 75 percent of the participants felt that the system was accurately providing feedback on their speeding behavior, only 49 percent indicated that they actually reduced their speed. It is important to note that 2 participants admitted to tampering with the device, and 9 received a speeding violation during the time when the speed monitoring/warning device was installed in their vehicle. It is important to note that during the data review process, any trip that had a tampering flag (see Section 4.4) or looked suspicious was removed from the data file.

Participants also provided some comments about the actual physical characteristics and functionality of the tiwiPro. The comments were aimed at increasing user acceptance and effectiveness. A summary of their comments are below: 
- The device could be more discreet in terms of size and color. Because it is secured to the windshield of the vehicle, decreasing its size and changing the color may minimize vandalism. Also, some participants found the size distracting when driving.

- The volume of the alert should be adjustable. When the alert was competing with ambient noises (e.g., radio, traffic), its effectiveness was diminished.

- Rather than have a mechanical voice as the alert, some suggested using a female voice similar to that used for GPS devices. Some also suggested that the alert be integrated into the vehicle's sound system.

- A visual alert should be paired with the audio alert.

- An LCD screen should be integrated into the system to provide information regarding both the posted speed limit on the roadway and the vehicle's speed.

- An App for the cell phone with similar functionality should made be available so it can limit the number of devices in use in the vehicle.

\subsection{Feasibility of a Larger Scalle Deployment}

A larger scale deployment of this speed monitoring/feedback system would be relatively straightforward in some respects; however, the discussion below outlines some of the issues and challenges that would need to be addressed when implementing such a program.

\subsubsection{Subject Recruitment}

Identifying and recruiting participants for such a program would be a demanding requirement. It first would involve identifying drivers that meet the speeding criteria, and then inducing them to participate. A key approach to addressing this issue would involve establishing a cooperative arrangement with sources that can easily identify and recruit participants. When selecting a potential source, one must be sensitive to concerns of the participants. Throughout the current study, participants expressed serious suspicions about third parties having access to their driving information. Participants felt that providing information to agencies other than researchers would only have negative consequences, including the revocation of their driver's license and increased insurance premiums. If the program is intended to involve voluntary participation, providing information to these agencies without the participants' consent would severely limit the likelihood of recruiting individuals. Conversely, it is important to note that some sources (e.g.; insurance companies) may be hesitant to disclose information about their client's driving behavior, concerned that this might alienate their clients by identifying their violations and flaws to a third party. In addition, a potential disadvantage of working with an insurance company is that insurance companies typically do not have the most up-to-date information about their customers' driving records. Our understanding is that it is common for insurance companies to check DMV records for traffic violations as infrequently as once a year.

Determining the incentive is another critical component of recruiting. While there are always budgetary and practical concerns when developing a program, the incentive needs to be appealing to the target population. The incentive should not only peak potential participants' interest in the program, but be appealing enough to maintain their cooperation for the duration of their participation in the program. The current study offered potential participants $\$ 150$ for a study with 
an 8 to 14 week duration. Although the goal of recruiting 80 participants was met, the response rate for the study was only 4 percent (271 calls/6,361 letters). A larger monetary incentive may have increased the overall response rates, and may need to be considered for a large scale program with a longer duration.

\subsubsection{Installation/Removal}

There are a number of pragmatic considerations that need to be addressed when identifying a speed monitoring/warning system that would be used for a large scale program. These would include: cost, availability, reliability, ease of installation and installation time. The installation time directly affects the number of participants that can be enrolled over a given time. In addition, easy and quick installations will reduce the burden on participants, increasing the likelihood of participation.

Installation of the tiwiPro devices is relatively simple. Most vehicles with an OBD-II port are compatible with the device and installation typically takes 20 minutes or less. However, it is important to note that some foreign make models had OBD-II ports that were not compatible with this device. For the current effort, the research team's technicians performed the installations. However, for a larger scale deployment, that would not need to be the case. Inthinc has an installation agreement with a variety of contract installers (e.g., Best Buy, etc.) which requires an individual to simply present a gift card-like coupon to an installer for fast and flexible installation. Once a physical installation is performed, the installer is required to perform a quick calibration and system reset that connects the device to the communication network and allows information to begin flowing. Everything else related to the installation setup can be accomplished remotely by the installer or other authorized personnel at that point.

Removal of the tiwiPro is generally easier than the installation, typically requiring less than 5 minutes by a technician. Again, this could be performed by a local installer at a retail facility or even with a home or office visit, depending on the technician.

\subsubsection{Mode Changes}

Each phase of a given installation required a manual action on the part of personnel at inthinc. In the case of this study, the research team communicated directly using email message to inthinc on the day that the alert mode needed to be changed and would get feedback confirming that the changes had been made. This level of interaction with inthinc would probably not be ideal for a larger scale effort. The ideal would be to have an interface module on the administrative portal that would allow the deployment administrator to make those changes themselves. This would alleviate some of the potential for delays, lost request messages, or data entry errors. This is not to say that there were a large number of these types of errors on the current project, but the removal of this step would improve the process. The administrative portal provides a large number of tools to set nearly every aspect of the user's experience. However, this one aspect is kept out of the administrator's hands, which reduces the overall efficiency of the process.

\subsubsection{Account Setup}

Each tiwiPro requires a cell phone account to allow transmission of data to a central server for tracking and reporting. As such, each unit incurs a monthly fee for the data transmission service that it uses. For the current study, these charges were invoiced monthly and ran approximately $\$ 30$ per 
unit per month. With larger numbers of units in a fleet and perhaps a steady, ongoing usage pattern, perhaps different carriers or billing schedules could be possible. Those details would have to be worked out with the vendor.

Once a cell phone account is set up for each device, setup involves providing information on the participant and vehicle. The current study used relevant nomenclature to identify each participant and their respective vehicles. Additionally, each vehicle required entry of at least a partial VIN to allow the tiwiPro to properly interpret the signals coming from the OBD-II port. Once the individual accounts are set up, the administrator is able to perform individual adjustments to parameters as needed. As such, with proper planning of a larger scale study, intuitive groupings of installed units could be handled quite efficiently.

\subsubsection{Data Delivery Format}

Data for the current effort were delivered as a continuous stream of "bread crumb" data on a daily basis. Although this was necessary for this study, it may not be required for a larger deployment. Depending on the data reporting or analysis needs, it may be sufficient to have simple reports of various speeding metrics delivered in report form, rather than as a huge set of raw data. For example, statistics could have been provided by inthinc with the ability to drill down via whatever variables are selected. The most relevant and indicative variables can be targeted and organized for presentation to participant monitors or administrators of such a program or study.

\subsubsection{Recycling Devices}

When tiwiPro were removed at the completion of the study, each needed to be readied for the next installation. Very little effort was required to put the devices back into service. This happened during the current effort with minimal glitches. For a larger effort, one of the best defenses against adverse or uninterpretable data is to maintain good records with tight, positive control over the status of each device so that historical records can be accessed in the event that quality control measures expose unusual situations or variations in some aspect of an individual's data.

\section{Conclusions and Discussion}

The present study aimed to determine the impact of short-term and long-term exposure to a speed monitoring/warning system on a driver's speeding behavior, and to explore the feasibility of implementing this type of program on a larger scale. The purpose of a speed monitoring/warning system is to discourage the driver from speeding by continuously comparing the vehicle speed to the posted speed limit, and alerting the driver when the vehicle speed surpasses a given threshold. While the cost and benefits of traditional countermeasures have been investigated over the years, the influence of in-vehicle technologies as a deterrent for speeding behavior remains unknown. If this technology is effective and efficient in suppressing speeding behavior, speed monitoring/warning systems might be able to supplement the more traditional countermeasures.

Examination of the current study's findings is encouraging, and suggests that the verbal alerts provided by the system were successful in producing statistically significant but small short-term changes in driving behavior. In the current study, the true measure of effectiveness of the system, in this study, is the change in average proportion of speeding over $8 \mathrm{mph}$ above the posted speed limit, 
which is the speed at which the threshold for the alert was set. Overall, the average proportion of speeding above the threshold declined significantly during the course of the treatment phase for drivers in the short-duration condition, indicating that the presence of audio alerts does have a deterring effect on speeding behavior. In addition, once the treatment was lifted, there was evidence suggesting a sustained change in driving behavior for some participants. Although the proportion of speeding above the threshold during the two week follow-up period was higher than the proportion of speeding during the treatment phase, the follow-up speeds were significantly lower than those recorded during the baseline phase.

Interestingly, the effects seemed to be similar for habitual speeders, where there was a decline in the proportion of speeding above the threshold during the treatment phase; however, the speeding behavior resumed once the alerts were removed. This group of drivers, on average, drove at speeds greater than $8 \mathrm{mph}$ over the speed limit for at least 30 percent of their baseline trips, and may be more willing to risk receiving a speeding violation. Thus, from a safety perspective, they may stand to benefit the most from using a speed monitoring/warning system.

It is also important to note that, while the significance of the effects for the long-duration condition could not be addressed with confidence due to the small sample size (five participants), the trends seem to echo those from the short-duration condition, providing preliminary evidence for the potential to use these systems as a tool for reducing speeding behavior. In addition, the follow-up period for the long-duration condition was four weeks as compared to two weeks for the shortduration condition. Given that the current study duration for each driver was only 8-14 weeks, the prolonged lasting effects of the alerts on driving behavior were not tested. Further research with longer duration treatment and follow-up measures may be necessary for understanding the true lasting effects of this type of system on driving behavior.

The second goal of this study was to explore the feasibility of implementing this type of voluntary program on a larger scale. Several factors must be considered when implementing a voluntary largescale program. These include factors related to the perceptions and motivations of the participants, and factors related to the success and practicality of the equipment, and the procedures required to implement, manage, and maintain the program. Voluntary use and influences on driver behavior may be influenced in opposite ways by the system features. That is, there are inherent trade-offs between the effectiveness of a device in producing a behavior change and the willingness of drivers to install and use the system. It is important to note that programs, such as the breath testing devices and mandatory seatbelt laws, were not adopted without significant debate and deliberation. Given that speeding is considered to be socially acceptable by many drivers, executing a large scale program may be met with similar challenges.

Based on the findings of this pilot study, recruiting volunteers and public acceptance may be an obstacle to implementing this type of program on a larger scale. A total of 6,321 recruitment letters were sent to individuals through the MVA and only 271 individuals expressed an interest. Although drivers were not worried about participating in a research study, drivers believed that providing information to agencies other than researchers would have only negative consequences, including the revocation of their driver's license and increased insurance premiums. If the program is intended to involve voluntary participation, providing information to these agencies would introduce severe recruiting challenges. 
However, there is reason to believe that public attitudes concerning the system are reasonably positive. When the topic of speed monitoring/warning systems was introduced during the focus group, some were not very accepting of the system, but most drivers indicated that they would consider using a speed warning/monitoring device as a method to help manage driving speeds. Once drivers had an opportunity to actually experience the device, a majority of the drivers reported having a positive experience. Drivers indicated that the device was accurate at monitoring their speed, and the alerts encouraged them to monitor their driving behavior more frequently. Conversely, the few who were dissatisfied with the system, felt that the threshold for alerts was set too low, and that it was not in line with prevailing traffic.

With regard to the functionality of the system used for the current study, drivers unanimously agreed that the volume of the alert was set too low and, at times, it was drowned out by ambient noise. Adjusting the volume may increase the effectiveness of the device. In addition, although this study did not experience many issues related to discrepancies between the database of posted speed limits and the driver's perception of the speed limit for a given roadway, it is essential that the database be maintained and current. If the driver loses confidence in the system, compliance will suffer.

Other practical considerations that need to be addressed include balancing the burden experienced by the driver with managing the different components of the study during the driver's participation. This would include installation and removal issues, implementing mode changes, and accessing data from the driver's in-vehicle system. Ideally, these aspects of the research study would be seamless to drivers, increasing the likelihood of their enrolling and continuing to participate.

While the above considerations can effect enrollments and participation rates, they also play a key role in data quality and acquisition. For example, mode change requests were communicated directly with inthinc. This level of interaction would not be recommended for a larger scale effort. The ideal would be to have an interface module that would allow the researcher or administrator to make those changes themselves. This would minimize delays, and data entry errors.

Overall, the current naturalistic driving study demonstrated that exposure to speeding alerts have a distinct effect on driver's speeding behavior, and that there are residual effects that linger for some time after the alerts are removed. Note that the treatment and follow-up phases of this study were not extensive, and that a longer duration period is recommended in order to test the long-lasting effects of this kind of system on driving behavior. While the design and methods adopted for conducting the current study were appropriate for this level of effort, it is recommended that some of the strategies be adjusted when dealing with a larger scale sample of chronic speeders. For example, requesting phase changes through the vendor might become unmanageable and difficult to track for a larger sample, monitoring for tampering and instances when driving data did not appear for more than 24 hours may also become time consuming, and the incentive level may need to be reexamined for a larger scale study of longer duration. 


\section{References}

Corbett, C. (2000). The social construction of speeding as not 'real' crime. Crime Prevention and Community Safety: An international Journal, 2(4), 33-46.

Chorlton, K., \& Conner, M. (2012). Can enforced behavior change attitudes: Exploring the influence of intelligent speed adaptation. Accident Analysis and Prevention, 48, 49-56.

Elvik, R., Christensen, P., \& Amundsen, A. (2004). Speed and road accidents: an evaluation of the power model. (TOI Research Repot 740/2004). Oslo, Norway: Institute of Transport Economics.

Jenness, J., Singer J., Walrath, J., \& Lubar,E. (2009). Fuel Economy Driver Interfaces: Design Range and Driver Opinions (Report No. DOT HS 811 092). Washington, DC: National Highway Traffic Safety Administration.

Lai, F., \& Carsten, O. (2012). What benefits does intelligent speed adaptation deliver: A close examination of its effect on vehicle speeds. Accident Analysis and Prevention, 48, 4-9.

Lerner, N., Singer, J., Huey, R., \& Jenness, J. (2007). Acceptability and Potential Effectiveness of Enhanced Seat Belt Reminder System Features. (Report No. DOT HS 810 848).

Washington, DC: National Highway Traffic Safety Administration.

Manser, M., Rakausskas M., Graving, J., \& Jenness, J..(2010). Fuel Economy Driver Interfaces: Develop Interface Recommendations (Report No. DOT HS 811 319). Washington, DC: National Highway Traffic Safety Administration.

McCartt, A., Farmer, C. M., \& Jenness, J. W. (2010). Perceptions and experiences f participants in a study of in-vehicle monitoring of teenage drivers. Traffic Injury and Prevention, 11, 361-370.

National Highway Traffic Safety Administration. (2006). Summary Report: Workshop on Vehicle Technologies to Aid Teen Drivers. (Report No. DOT HS 810 612). Washington, DC: Author.

Reagan, I. J., (2011) A field experiment to test the effects of automated feedback and monetary incentive on speeding behavior. Ph.D. Dissertation. Old Dominion University, Norfolk, Va.

Reagan, M. A., Triggs, T. Young, K. L., Tomasevic, N., Mitsopoulos, E., Stephan, K., \& Tingvall, C. (2006) On-road evaluation of intelligent speed adaptation, following distance warning and seatbelt reminder systems: final results of the TAC SafeCar (Project. Report No. 253). Victoria, Australia: Monash University Accident Research Centre.

Webster, D., \& Wells, P. (2000). The characteristics of speeders. (TRL Report 440). Crowthorne, U.K.: Transport Research Laboratory. 
Zuckerman, M., \& Neeb, M. (1980). Demographic influences in sensation seeking and expressions of sensation seeking in religion, smoking, and driving habits. Personality and Individuals Differences, 1, 197-206. 


\section{Appendix}

\section{Explanation of Statistical Approach}

Traditional repeated measures ANOVA (or related MANOVA) approaches make several assumptions, such as equal time spacing and equal variance/covariance, as well as use ordinary least squares to test fixed effects. They also assume compound symmetry covariance, which is often untrue (especially if the data are not based on equal time spacing). A mixed model approach has several advantages: a) testing of fixed effects using generalized least squares which results in more powerful tests, b) ability to better handle missing data and unequal time spacing, c) allowance for covariance analysis, and d) allows flexibility in modeling the covariance. This last point is a particularly strong advantage in the current case, where a better fitting covariance structure for the data was ante-dependence, but not the default compound symmetry often assumed in traditional repeated measures approaches.

Logit transforms were performed instead of the more common arcsin transforms. Arcsin transforms can have limitations on interpretation, and were not a good fit for many of the variables in the subsequent analyses. Logit transformations provide a better interpretation basis, better fit to normality, and also map proportions y E $[0,1]$ monotonically to the whole real line $(-\infty, \infty)$. A logit transformation was performed on the dependent variables for better approximation of normality. Logit transforms, [log $(\mathrm{y} / \mathrm{c}-(1-\mathrm{y} / \mathrm{c})]$ where $\mathrm{y}$ is the dependent variable and $\mathrm{c}$ is a constant $(=1 \mathrm{in}$ this case), are useful for analyzing data between 0 and 1 . It will smooth or decrease extreme values and increase the middle of the curve.

A Sidak p-value adjustment was used, which is $1-\left(1-p_{r}\right)^{R}$, where $p$ is the $p$ value and $R$ is the number of statistical tests. An adjustment method is advised when there are multiple comparisons, due to the multiplicity problem - increased likelihood of witnessing a rare event, thereby increasing the chance of rejecting the null hypothesis when it is true (Type 1 error). Ante-dependence covariance, parms $=2 t-1$ and $i, j$ elements $=\sigma_{i} \sigma_{j} \prod_{k=i}^{j=1} \rho_{k}$, where $t=$ overall dimension of the matrix, and $\sigma=$ covariance, $\varrho=$ correlation, is a type of covariance structure with heterogenous variances and correlations between adjacent elements and is considered a superior covariance structure option (e.g., Ser, 2012). 

DOT HS 811996

May 2014 